\title{
Ultrasound-Mediated Surface Engineering of Theranostic Magnetic Nanoparticles: An Effective One-Pot Functionalization Process Using Mixed Polymers for siRNA Delivery
}

Liron L. Israel' ${ }^{1}$ Emmanuel Lellouche ${ }^{2}$, Jean-Marc Grenèche ${ }^{3}$, Moshe Bechor ${ }^{2}$, Shulamit Michaeli* and Jean-Paul Lellouche ${ }^{1 *}$

${ }^{1}$ Department of Chemistry and Institute for Nanotechnology and Advanced Materials, Bar-Ilan University, Ramat-Gan 5290002, Israel

${ }^{2}$ Faculty of Life Sciences and Institute for Nanotechnology and Advanced Materials, Bar-llan University, Ramat-Gan 5290002, Israel

${ }^{3}$ Laboratoire de Physique de l'Etat Condensé, UMR CNRS 6087, UniVersité du Maine, Le Mans 72085, France

\begin{abstract}
Nano-sized materials have been studied for diverse clinical applications, partly because their size-dependent physical properties and nanometer-scale dimensions have important roles in biological systems. Synergistic combinations of differently nanostructured materials, such as polymer-coated magnetic nanoparticles (NPs), strongly promoted various multifunctional nano-medical platforms for simultaneous diagnosis and therapy in the rapidly emerging area of theranostics.

In this context, magnetically responsive Ce cation-doped maghemite $\left(\gamma-\mathrm{Fe}_{2} \mathrm{O}_{3}\right) \mathrm{NPs}$ form a useful NPs basis towards a new type of polycationic polymer/organic species-grafted maghemite NPs for both drug delivery and imaging. The versatility of the Ce cation-doped maghemite NPs fabrication process mediated by high-power ultrasound (US) enables the development of a new one-step time-saving US-driven variant fabrication of corresponding polymer/organic species-grafted NPs. Thus, two types of organic polycationic species, a branched $25 \mathrm{kDa}$ polyethylene imine $\left(b-\mathrm{PEI}_{25}\right)$ polymer and a generation 2 (G2) PAMAM (poly(amidoamine)) dendrimer biopolymer, were simultaneously used during this US-mediated NPs system fabrication to effectively deliver optimized small interfering RNA (siRNA) applications as a proof of concept. This unique one-step fabrication protocol affords a positively charged magnetic core grafted with mixed organic species nanocomposite particles that enables both gene silencing therapy and magnetic resonance imaging.
\end{abstract}

Keywords: Synergistic combined engineering of polymers; Magnetic nanocarriers; Gene silencing; Magnetic resonance imaging; CANmaghemite nanoparticles drug delivery systems; Toxicity mitigation of nanoparticles, Polyethylene imine (PEI) polymers; Design of experiments (DoE); Statistical experimental design

\section{Introduction}

Nano-sized materials are currently designed and fabricated for a wide range of diverse clinical applications. Synergistic combinations of differently nanostructured materials such as polymer-coated magnetic nanoparticles (NPs) can be readily optimized for corresponding multifunctional nano-medical platforms that enable simultaneous diagnosis and therapy, used for the rapidly emerging area of theranostics $[1,2]$.

Iron oxide NPs are the basis for many biomedical [3] applications [4] such as diagnostic magnetic resonance imaging (MRI), drug delivery systems, stem cell tracking, heat source hyperthermia [5] and more. Interestingly, selected small functional iron oxide NPs (in the size range of 5-30 nm) are now commercially available and FDA-approved [6] for clinical use (mainly MRI). In this context, numerous in vitro toxicity studies concerning different iron oxide particles functionalized by a great variety of polymers $[7,8]$ such as polyethylene imine (PEI) [9] PVA (polyvinyl alcohol), PLL (poly- $L$-lysine), PDMA (poly $N, N$ dimethylacrylamide) and PEGs (polyethylene glycols) [10] have recently been reviewed, showing the major importance of correctly designed NPs surface engineering.

Maghemite $\left(\gamma-\mathrm{Fe}_{2} \mathrm{O}_{3}\right)$ is a red-brown magnetic mineral that can be readily produced by direct oxidation of a corresponding magnetite $\left(\mathrm{Fe}_{3} \mathrm{O}_{4}\right)$ phase. In an earlier work, hydrophilic and strongly positively charged non-aggregated $\gamma$ - $\mathrm{Fe}_{2} \mathrm{O}_{3}\left(\mathrm{CAN}-\gamma\right.$ - $\left.\mathrm{Fe}_{2} \mathrm{O}_{3}\right)$ NPs were produced using a high-power ultrasonic (US) reaction of preformed Massart magnetite NPs with ceric ammonium nitrate $\left(\mathrm{CAN}, \mathrm{Ce}\left(\mathrm{NH}_{4}\right)_{2}\left(\mathrm{NO}_{3}\right)_{6}\right)$. This strong mono-electronic CAN oxidant enabled an easy oxidation of the starting $\mathrm{Fe}_{3} \mathrm{O}_{4}$ phase together with a controlled Ce cation/complex NPs surface doping, resulting in an effective NPs aggregation control (high positive charge repulsion) and coordinative attachment (Ce cation/complex ligand exchange) of any Lewis base-behaving organic species [11].

Therefore, the non-toxic/biocompatible crystalline hydrophilic and positively charged $(+43.0-+53.0 \mathrm{mV})$ Ce cation/complex-doped $\gamma$ - $\mathrm{Fe}_{2} \mathrm{O}_{3}$ NPs were readily obtained as extremely stable colloidal aqueous NPs dispersions. The resulting NPs are superparamagnetic with a measured $r_{2}^{*}$ relaxivity value of $189 \mathrm{mmol} \mathrm{s}$ [11-14] which makes this nanosystem a potentially suitable candidate for medical applications such as MRI [15,16] magnetic hyperthermia [5] and drug delivery $[17,18]$. Such resulting $\mathrm{CAN}-\gamma-\mathrm{Fe}_{2} \mathrm{O}_{3} \mathrm{NPs}$ may readily form a nanosized basis for polymer/organic species-grafted CAN- $\gamma$ - $\mathrm{Fe}_{2} \mathrm{O}_{3}$ NPs that may be optimized for drug delivery purposes together with attractive MRI capabilities. As a methodological proof of concept,

*Corresponding authors: Jean-Paul Lellouche, Department of Chemistry and Institute for Nanotechnology and Advanced Materials, Bar-llan University, Ramat-Gan 5290002, Israel, Tel: 972-54-7-258 188; E-mail: jean-paul.m.lellouche@biu.ac.il

Shulamit Michaeli, Faculty of Life Sciences and Institute for Nanotechnology and Advanced Materials, Bar-Ilan University, Ramat-Gan 5290002, Israel, Tel: 972-3-531 83 07; E-mail: Shulamit.Michaeli@biu.ac.il

Received June 13, 2016; Accepted June 16, 2016; Published June 23, 2016

Citation: Israel LL, Lellouche E, Grenèche J, Bechor M, Michaeli S, et al. (2016) Ultrasound-Mediated Surface Engineering of Theranostic Magnetic Nanoparticles: An Effective One-Pot Functionalization Process Using Mixed Polymers for siRNA Delivery. J Nanomed Nanotechnol 7: 385. doi:10.4172/2157-7439.1000385

Copyright: ( 2016 Israel LL, et al. This is an open-access article distributed unde the terms of the Creative Commons Attribution License, which permits unrestricted use, distribution, and reproduction in any medium, provided the original author and source are credited. 
Citation: Israel LL, Lellouche E, Grenèche J, Bechor M, Michaeli S, et al. (2016) Ultrasound-Mediated Surface Engineering of Theranostic Magnetic Nanoparticles: An Effective One-Pot Functionalization Process Using Mixed Polymers for siRNA Delivery. J Nanomed Nanotechnol 7: 385. doi:10.4172/2157-7439.1000385

Page 2 of 14

small interfering RNA (siRNA) delivery was chosen as the biologydriven platform for testing and optimizing CAN- $\gamma$ - $\mathrm{Fe}_{2} \mathrm{O}_{3}$ NPs surface grafting procedures, including process robustness for potentially useful biomedical capabilities.

In the field of nucleic acid delivery systems, RNA interference (RNAi) is a highly efficient regulatory process, which causes gene silencing in most eukaryotes. Two types of RNAi exist in nature, siRNAs and micro-RNAs (miRNAs). Both use the RNA-induced silencing complex (RISC) to induce messenger RNA (mRNA) degradation. However, despite the potentially high therapeutic advantages of siRNAs, such therapies are not yet available in the clinics. Following intravenous injection, naked and unmodified siRNAs can be readily degraded by endonucleases, be excreted by renal clearance, or even cause undesirable off-target effects [19]. In addition, due to their large molecular weights ( $\mathrm{MW}$, of $\otimes 13 \mathrm{kDa}$ ), negative charges and hydrophilic nature, siRNA molecules are unable to cross cell membranes by passive diffusion mechanisms. These limitations have led to the development of a wide range of nanocarriers, including cyclodextrin polymers, [2023] lipid-based carriers, $[24,25]$ dendrimers, [25,26] neutral or cationic polymers, $[27,28]$ conjugated-siRNAs $[29,30]$ and various nanoparticle formulations [31-33]. The polycationic branched polyethyleneimine polymer (branched PEI, $25 \mathrm{kDa}-b-\mathrm{PEI}_{25}$ ) is one of the most common and efficient transfecting agents for the electrostatic capture and delivery of nucleic acids and was therefore chosen for this versatile NPs surface engineering.

In a former study, [11] $b$ - $\mathrm{PEI}_{25}$-coated $\mathrm{CAN}-\boldsymbol{\gamma}-\mathrm{Fe}_{2} \mathrm{O}_{3} \mathrm{NPs}$ were fabricated using Lewis acid Ce cation/complex-based coordination chemistry (ligand exchange reaction) to bind Lewis base PEI species onto a doping Cecation/complex shell present on the NPs surface (twostep process). In a more recent work, several surface modifications were performed on resulting $b$ - $\mathrm{PEI}_{25}$-coated CAN- $\gamma$ - $\mathrm{Fe}_{2} \mathrm{O}_{3} \mathrm{NPs}$ and a selected statistically significant DoE (Design of experiments) study was conducted in order to mitigate the $b$ - $\mathrm{PEI}_{25}$ known acute in vivo toxicity [34] (Scheme 1 - Former method A). Without any additional chemical modification of the $b-\mathrm{PEI}_{25}$ shell or DoE processing related to NPs surface engineering, the resulting $b$ - $\mathrm{PEI}_{25}$-coated NPs fabricated via coordination chemistry were toxic in vivo even at a low dose of $1 \mathrm{mg} / \mathrm{kg}$ siRNA (mice died within two hours after NPs intravenous injection).

In order to even shorten the overall process of NPs fabrication, a new NPs surface engineering procedure was tested, in which the polycationic $b-\mathrm{PEI}_{25}$ polymer was injected directly into the ultrasonicated CAN/magnetite reaction vessel during the Ce cation/ complex NPs surface doping reaction [35] (Scheme 1 and Supporting

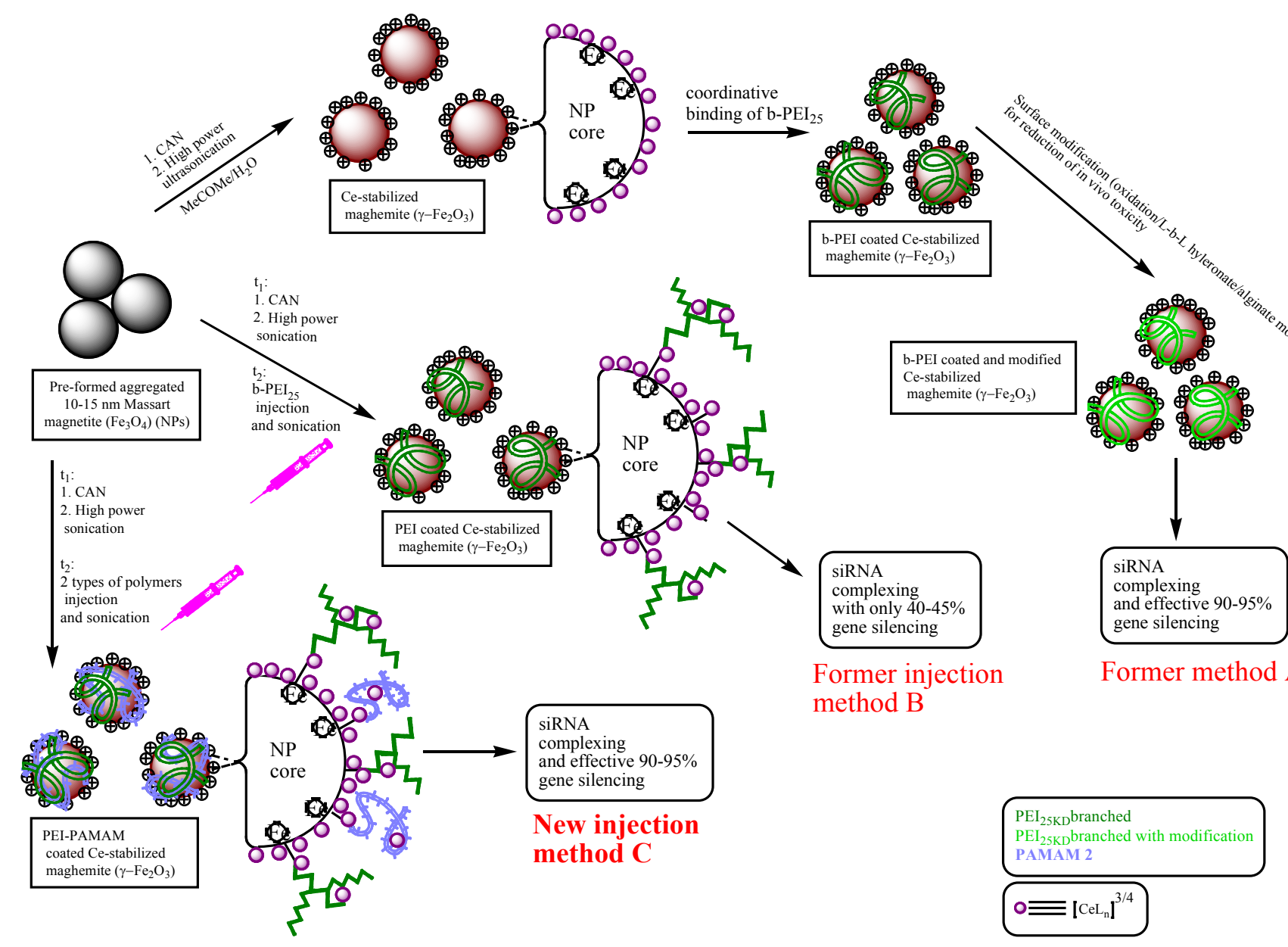

Scheme 1: Illustrative scheme of polymer/organic species grafting onto CAN-maghemite NPs: Former method $A^{34}$ (three steps with effective gene silencing capabilities), former injection method $B^{35}$ (one step with one involved polymer, medium-level gene silencing capabilities) and the new injection method $C$ (one step, involvement of several polymers with very effective gene silencing capabilities). 
Citation: Israel LL, Lellouche E, Grenèche J, Bechor M, Michaeli S, et al. (2016) Ultrasound-Mediated Surface Engineering of Theranostic Magnetic Nanoparticles: An Effective One-Pot Functionalization Process Using Mixed Polymers for siRNA Delivery. J Nanomed Nanotechnol 7: 385. doi:10.4172/2157-7439.1000385

Page 3 of 14

Information (SI)-B, Former injection method B). This robust one-step protocol considerably shortened the expected NPs fabrication time $(1 \mathrm{~h})$ to afford stable $b$ - $\mathrm{PEI}_{25}$-grafted magnetic NPs $(M s: 49.0 \mathrm{emu} / \mathrm{g})$ with a highly positive $\zeta$ potential value (up to $+56.3 \mathrm{mV}$ ). However, in this case, in vitro gene silencing resulted in a significantly lower (40$45 \%)$ level when compared to the one obtained using the more effective A-fabricated (coordination chemistry) $b$ - $\mathrm{PEI}_{25}$-coated CAN- $\gamma$ - $\mathrm{Fe}_{2} \mathrm{O}_{3}$ NPs (90-95\% gene silencing) method.

In order to address and solve this effectiveness issue, various polycationic polymers at variable weight ratios were simultaneously introduced during the high-power US-mediated NPs reaction to further extend and optimize this new one-step method.

Therefore, in the present study (one-step injection method C), both $25 \mathrm{kDa}$ branched polyethyleneimine $\left(b-\mathrm{PEI}_{25}\right)$ and the polyaminated generation 2 (G2) PAMAM (poly(amidoamine)) dendrimer [36] phase were used and tested for NPs decoration together with gene silencing capabilities and NPs toxicity mitigation. As mentioned above, the highly positively charged $b$ - $\mathrm{PEI}_{25}$ (Scheme 2 ) is one of the most effective known polycationic transfection polymers [37]. In addition, the second coating polycationic component, a spherical highly branched G2 PAMAM dendrimer (Scheme 2), was chosen to potentially reduce the overall NPs toxicity and to increase NPs-mediated gene silencing capabilities. Consequently, this new one-step NPs decoration process allowed both $b$-PEI ${ }_{25}$ polymer and G2 PAMAM dendrimer species to be directly introduced into the US reaction vessel (injection process) [35] to promote versatile $\gamma$ - $\mathrm{Fe}_{2} \mathrm{O}_{3} \mathrm{NPs}$ surface decoration.

\section{Experimental Section}

\section{Materials}

The specific chemicals and reagents (analytical grade and highest purity level) used in this study, $\mathrm{FeCl}_{3} \cdot 6 \mathrm{H}_{2} \mathrm{O}, \mathrm{FeCl}_{2} \cdot 4 \mathrm{H}_{2} \mathrm{O}, \mathrm{NH}_{4} \mathrm{OH}$ (ACS reagent, 28-30\%), CAN $\left(\mathrm{Ce}\left(\mathrm{NH}_{4}\right)_{2}\left(\mathrm{NO}_{3}\right)_{6}\right)$, chitosan (low molecular weight) and branched polyethyleneimine $\left(b-\mathrm{PEI}_{25}, \mathrm{MW} \approx\right.$ $25 \mathrm{kDa}$ ) were purchased from Sigma-Aldrich (Israel) and were used without any further purification.

\section{Fabrication protocols}

Starting neat neutral magnetite $\left(\mathrm{Fe}_{3} \mathrm{O}_{4}\right)$ nanoparticles $\left(\mathrm{Fe}_{3} \mathrm{O}_{4}\right.$ NPs, basic Massart hydrolytic method):A solution of $\mathrm{FeCl}_{3} \cdot 6 \mathrm{H}_{2} \mathrm{O}$ (240.0 mg, $0.9 \mathrm{mmol}$ ) dissolved in degassed Milli-Q purified $\mathrm{H}_{2} \mathrm{O}(4.5$ $\mathrm{mL})$ was mixed with an aqueous solution of $\mathrm{FeCl}_{2} \bullet 4 \mathrm{H}_{2} \mathrm{O}(97.5 \mathrm{mg}, 0.45$ mmol, $4.5 \mathrm{~mL} \mathrm{H}_{2} \mathrm{O}$ ). This solution was kept under $\mathrm{N}_{2}$ and ultrasonicated (Bransonic ${ }^{\circledast}$ ultrasonic cleaner bath, 2510E MTH model, $42 \mathrm{KHz}$ at full power) for 5-10 $\mathrm{min}$ at room temperature. Then, a concentrated $24 \%$ weight aqueous $\mathrm{NH}_{4} \mathrm{OH}(0.75 \mathrm{~mL})$ was introduced in one shot, resulting in an immediate black precipitation of magnetite $\left(\mathrm{Fe}_{3} \mathrm{O}_{4}\right)$ NPs. The sonication was continued for an additional 10 minutes. The resulting $\mathrm{Fe}_{3} \mathrm{O}_{4}$ NPs were transferred into a glass bottle $(100 \mathrm{~mL})$, magnetically decanted (using a strong external magnet) and washed with $\mathrm{ddH}_{2} \mathrm{O}(3 \times 40 \mathrm{~mL})$ until reaching neutrality. Then, brilliant-black free-flowing magnetite NPs were stored as a $60 \mathrm{~mL}$ NP suspension in degassed Milli-Q purified $\mathrm{H}_{2} \mathrm{O}$ before any further processing. At this point, an aging process must be executed for a minimum storage time of 2 hours under the above-mentioned conditions (room temperature).

CAN-stabilized maghemite nanoparticles (CAN- $\gamma-\mathrm{Fe}_{2} \mathrm{O}_{3}$ NPs): First, the former aqueous magnetite $\mathrm{N}$ suspension $(20 \mathrm{~mL})$ was magnetically decanted to separate the magnetite NPs from the aqueous storage phase. $\mathrm{CAN}\left(\left(\mathrm{NH}_{4}\right)_{2} \mathrm{Ce}(\mathrm{IV})\left(\mathrm{NO}_{3}\right)_{6}, 100 \mathrm{mg}, 0.181\right.$ mmol) dissolved in $4.0 \mathrm{~mL}$ MeCOMe was introduced into decanted magnetite NPs, followed by the addition of degassed Milli-Q purified $\mathrm{H}_{2} \mathrm{O}(4.0 \mathrm{~mL})$. The corresponding mixture was ultrasonicated using a high-power sonicator (Sonics ${ }^{\oplus}$, Vibra cell, 750 Watt, power modulator set-up at $25 \%)$ equipped with a titanium horn $\left(1 \mathrm{~h}, 0^{\circ} \mathrm{C}\right)$ and under an inert argon atmosphere.

At this stage, and optionally, the resulting highly stabilized hydrophilic CAN- $\gamma-\mathrm{Fe}_{2} \mathrm{O}_{3}$ NPs are purified : washing with $\mathrm{ddH}_{2} \mathrm{O}(3$ x $10 \mathrm{~mL}$ ) using an Amicon Ultra-15 centrifugal filter device $(100 \mathrm{~K})$ processed at $4,000 \mathrm{rpm}$ for $5-6 \mathrm{~min}\left(18^{\circ} \mathrm{C}\right)$ and re-dispersed in Milli-Q purified $\mathrm{H}_{2} \mathrm{O}(15 \mathrm{~mL})$

DoE-optimized ${ }_{\text {inj }}$ PEI $_{25} /$ PAMAM $_{62}-\mathrm{CAN}-\boldsymbol{\gamma}-\mathrm{Fe}_{2} \mathrm{O}_{3}$ NPs: First, the former aqueous magnetite NP suspension $(20 \mathrm{~mL})$ was magnetically decanted to separate the magnetite NPs from the aqueous storage phase. CAN $\left(\left(\mathrm{NH}_{4}\right)_{2} \mathrm{Ce}(\mathrm{IV})\left(\mathrm{NO}_{3}\right)_{6}, 81.57 \mathrm{mg}, 0.148 \mathrm{mmol}\right)$ dissolved in $6.0 \mathrm{~mL} \mathrm{MeCOMe}$ was introduced onto decanted magnetite NPs, followed by the addition of degassed Milli-Q purified $\mathrm{H}_{2} \mathrm{O}(2.0 \mathrm{~mL})$. The corresponding mixture was ultrasonicated using a high-power sonicator (Sonics ${ }^{\oplus}$, Vibra cell, 750 Watt, power modulator set-up at $25 \%)$ equipped with a titanium horn $\left(50 \mathrm{~min}, 0^{\circ} \mathrm{C}\right)$ under an inert atmosphere. Then, the $b-\mathrm{PEI}_{25}(15.0 \mathrm{mg}, 0.569 \mu \mathrm{mol}, 10 \mathrm{mg} / \mathrm{mL}$ aqueous solution) and the PAMAM $_{\mathrm{G} 2}(5.0 \mathrm{mg}, 1.535 \mu \mathrm{mol}, 20 \% \mathrm{wt}$ in $\mathrm{MeOH}$ ) were added, and high power ultrasonication was continued for 10 additional minutes. The resulting NPs were purified by washing with Milli-Q purified $\mathrm{H}_{2} \mathrm{O}(3 \times 10 \mathrm{~mL})$ using Amicon ${ }^{\circledR}$ Ultra- 15 centrifugal filter devices $(100 \mathrm{~K})$ processed at $4,000 \mathrm{rpm}$ for $5-6 \mathrm{~min}\left(18{ }^{\circ} \mathrm{C}\right)$, followed by a size exclusion step by centrifugation $(8000 \mathrm{rpm}, 10 \mathrm{~min}$, $18{ }^{\circ} \mathrm{C}$ ), where the supernatants were kept and the solid precipitation discarded. The NPs were dispersed in Milli-Q purified $\mathrm{H}_{2} \mathrm{O}(12 \mathrm{~mL})$ for storage.

\section{Nanocarrier functionalization using various siRNA species for delivery/gene silencing.}

Cell lines and culture: U2OS human osteosarcoma cells were obtained from the American Type Culture Collection (ATCC). The cells were cultured in Dulbecco's Modified Eagle Medium (DMEM) and supplemented with $10 \%$ fetal bovine serum, $100 \mu \mathrm{g} / \mathrm{ml}$ penicillin, $100 \mathrm{U} /$ $\mathrm{ml}$ streptomycin and $2 \mathrm{mM} \mathrm{L}$-glutamine (Biological Industries Ltd., Israel). The dual luciferase-expressing U2OS cell line (U2OS-Luc) was generated as previously described. All cells were grown at $37^{\circ} \mathrm{C}$ in $5 \% \mathrm{CO}_{2}$.

Luciferase assays: U2OS-Luc cells $(1 \times 10$ cells/well) were seeded in a 96 well optical bottom plate (Thermo) and incubated overnight at 37 $\mathrm{C}$ with $5 \% \mathrm{CO}_{2}$. The cells were transfected with Firefly luciferase siRNA $(100 \mathrm{nM})(0.166 \mu \mathrm{g})$ mixed with ${ }_{\mathrm{inj}} \mathrm{PEI}_{25} / \mathrm{PAMAM}_{\mathrm{G} 2}-\mathrm{CAN}-\gamma-\mathrm{Fe}_{2} \mathrm{O}_{3}$ NPs before and after the DoE optimization, at different $\mathrm{Fe} / \mathrm{siRNA} \mathrm{w} / \mathrm{w}$ ratios, or with no NPs (control). Forty-eight hours later, the cells were assayed for both Firefly and Renilla luciferase activities, as described elsewhere [11]. The following oligonucleotide sequences (sense/ antisense) were used: 5'-GGACAUCACCUAUGCCGAGUACUTC-3 and 5 '-CACCUGUAGUGGAUACGGCUCAUGAAG-3' (IDT Technologies).

The experiments were performed in the same manner as previously described (Israel et al.).

\section{In vivo experiments}

All animal experiments were performed in compliance with the Guidelines for the Care and Use of Research Animals established by the Bar-Ilan University Animal Studies Committee. BALB/c mice 


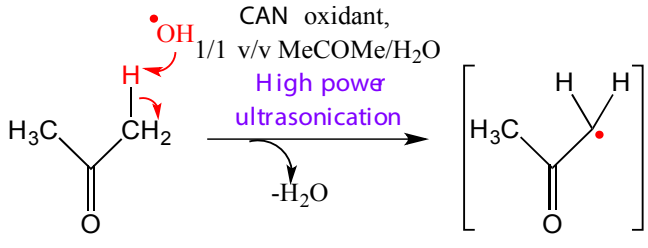

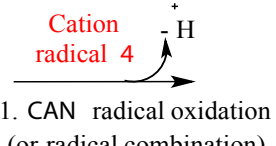

(or radical combination) 2. $\mathrm{H}_{2} \mathrm{O}$ nucleophilic addition

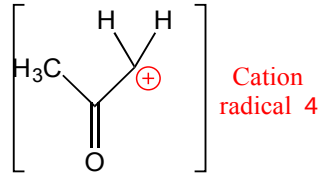

$\mathrm{R}=\mathrm{PEI} / \mathrm{PAMAM} \mathrm{G}_{2}$

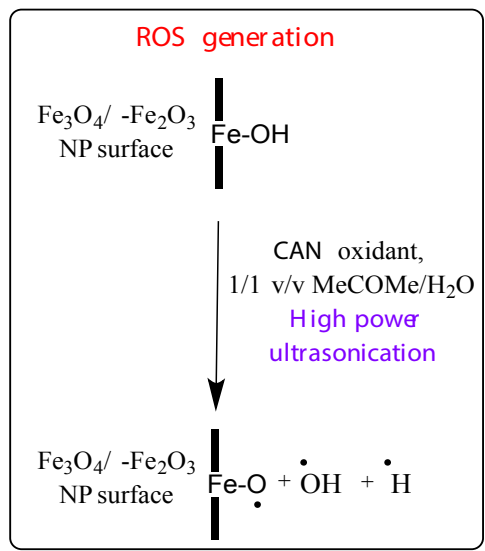

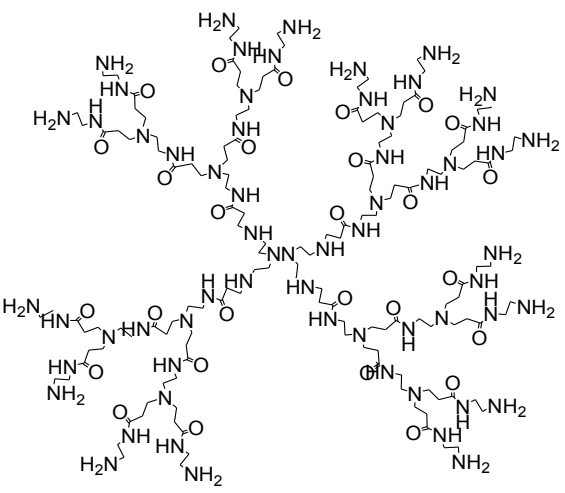

PAMAM Generation 2.0

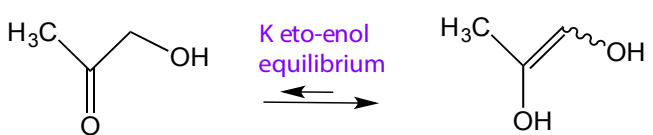

1-Hydroxypropan-2-one 5

Prop-1-ene-1,2-diol 6

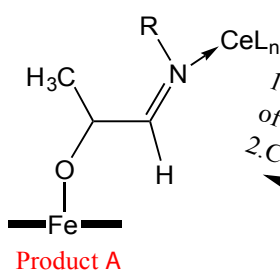

Product A
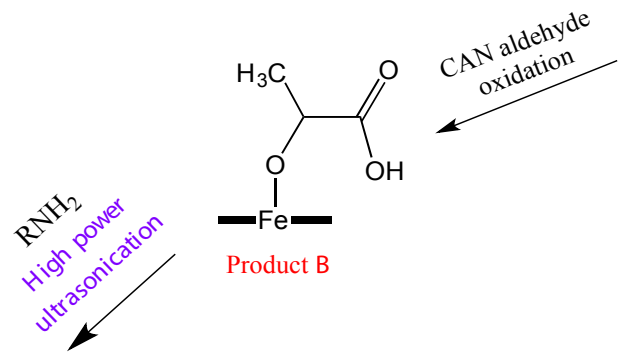

Product B

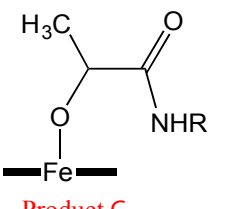<smiles>NCCNCCN(CCNCCN)CCN(CCNCCN)CCN(CCN)CCN</smiles>

PEI branched

Scheme 2: Illustrative scheme of the fabrication of PEI/PAMAM grafted CAN-maghemite NPs (top, "one-step injection process - method C") including PEI and G2 PAMAM chemical structures (bottom).

(Harlan Laboratories Israel Ltd., Jerusalem, Israel) aged 8-9 weeks were intravenously injected with NPs mixed with different doses of siRNA and different $\mathrm{Fe} / \mathrm{siRNA}$ w/w ratios or saline alone. All intravenous injections to mice were performed with RAC1 siRNA (this sequence was used only for acute in vivo toxicity screening). Each group was comprised of four mice and acute toxicity was defined as animal death following the $i v$ injection. The oligonucleotide sequences which were used were provided by Quark Pharmaceuticals Inc., Israel.

\section{Methods}

Mössbauer spectrometry: The samples were investigated by $\mathrm{Fe}$ Mössbauer spectrometry at $77^{\circ} \mathrm{K}$ using a transmission conventional 
Citation: Israel LL, Lellouche E, Grenèche J, Bechor M, Michaeli S, et al. (2016) Ultrasound-Mediated Surface Engineering of Theranostic Magnetic Nanoparticles: An Effective One-Pot Functionalization Process Using Mixed Polymers for siRNA Delivery. J Nanomed Nanotechnol 7: 385. doi:10.4172/2157-7439.1000385

device with a Co source diffused into a Rh matrix. The hyperfine parameters were refined by using quadrupolar doublets and magnetic sextets with lorentzian lines. The values of isomer shift are quoted to that of $\alpha$-Fe at room temperature.

X-ray photoelectron (XPS), FT-IR, and inductively coupled plasma atomic emission (ICP-AES) spectroscopies as well as thermogravimetry (TGA) requested the preparation of dry powder samples (vacuum stove $1 \mathrm{~h}$ at $40^{\circ} \mathrm{C}$ followed by lyophilization using a ScanVan coolsafe 4 liter bench-top freeze dry system). High-power ultra-sonication reactions were conducted using a high-power ultra-sonicator (Sonics, Vibra cell, 750 Watt, power modulator set-up at $25 \%$ ) equipped with a titanium horn under an argon atmosphere. Samples for low and highresolution TEM analyses were prepared by spreading a small drop of aqueous maghemite-based NPs dispersions on amorphous carboncoated copper grids (Formvar carbon 400 mesh grids, SPI ${ }^{\circledR}$ Supplies West Chester, USA) followed by air-drying.

Transmission Electron Microscopies at low and high resolutions (TEM/HR-TEM) made use of both JEM 1400 and 2100 (JEOL USA Inc.) microscopes (200 kV acceleration voltage, $2 \times 2 \mathrm{k}$ and $4 \times 4 \mathrm{kCCD}$ cameras respectively).

FT-IR spectra were recorded using a Bruker TENSOR 27 spectrometer (Diffuse Reflectance Accessory EasyDiff, PIKE Technologies, $4 \mathrm{~cm}^{-1}$ resolution). Samples were prepared by mixing NPs powders with dry IR grade $\mathrm{KBr}(2 \%$ weight).

DLS (hydrodynamic NP average diameter) and $\zeta$ potential measurements have been performed using (i) a Zetasizer Nano-ZS (Malvern Instruments Ltd, UK) employing a nominal $5 \mathrm{~mW} \mathrm{He-Ne}$ laser (operating wavelength: $633 \mathrm{~nm}, 20^{\circ} \mathrm{C}$, triplicate measurements), and (ii) disposable DTS1060C-Cleare $\xi$ cells $\left(\mathrm{ddH}_{2} \mathrm{O}, 25^{\circ} \mathrm{C}\right)$

ICP-AES elemental analyses have been run using a ULTIMA 2 spectrometer (HORIBA, Jobin Yvon Inc.).

Surface-sensitive X-ray photoelectron spectroscopy (XPS) analyses have been executed using a Kratos Axis HS apparatus equipped with Kratos "Vision 2" package software. NPs samples deposited onto a double-sided carbon-based self-adhesive tape (complete coverage) have been loaded in a ultra-high vacuum chamber $(5 \times 10-10$ Torr).

Thermogravimetric analyses (TGA) have been processed using a TGA/DSC1 analyzer (N2 atmosphere $/ 50 \mathrm{~mL} / \mathrm{min}$ at a heating rate of $10^{\circ} \mathrm{C} / \mathrm{min}$, Mettler-Toledo, OH, USA). Dry NPs samples $(8-10 \mathrm{mg})$ afforded TGA thermograms and corresponding weight loss derivative function graphs in a $25-900^{\circ} \mathrm{C}$ temperature range.

Magnetism (saturation magnetizations Ms, coercivity factors $\mathrm{Hc}$ including $\mathrm{ZFC} / \mathrm{FC}$ graphs/H=100 Oe) analyses have been obtained using a SQUID Quantum Design magnetometer (MPMS XL model operated in a 2 to $400^{\circ} \mathrm{K}$ temperature range with magnetic fields up to $5.5 \mathrm{~T}$ ).

\section{Results and Discussion}

\section{$\mathrm{Ce}^{3 / 4+}$ cation/complex doping and polymer-related modifications of $\gamma$ - $\mathrm{Fe}_{2} \mathrm{O}_{3} \mathrm{NPs}$}

Briefly, magnetite NPs were prepared using a Massart [38] coprecipitation process with $\mathrm{Fe}$ and $\mathrm{Fe}$ cation basic mixtures. The corresponding CAN-maghemite NPs aqueous suspension arising from the CAN-mediated high-power ultrasonication of former Massart magnetite NPs $\left(20 \mathrm{~mL}\right.$, Sonics ${ }^{\oplus}$, Vibracell, 750 Watt, power modulator set-up at $25 \%$, Titanium horn, $45 \mathrm{~min}$ irradiation, $0^{\circ} \mathrm{C}$, dry inert $\mathrm{Ar}$ atmosphere) was added at $\mathrm{t}=45 \mathrm{~min}$ to two types of reagent mixtures: $10.0 \mathrm{mg}$ of $b-\mathrm{PEI}_{25}\left(0.00032 \mathrm{mmol}, 10 \mathrm{mg} / \mathrm{mL} \mathrm{ddH}_{2} \mathrm{O}\right.$ solution $)$ and $10.0 \mathrm{mg}$ of G2 PAMAM dendrimer $(0.00307 \mathrm{mmol}, 0.058 \mathrm{~mL}$ of

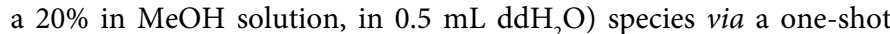
mixture injection into the US reaction medium. Next, high-power ultrasonication was continued for 15 additional minutes under the same reaction conditions. The resulting hydrophilic highly stable browncolored ${ }_{i n j} \mathrm{PEI}_{25} / \mathrm{PAMAM}_{\mathrm{G}_{2}}-\mathrm{CAN}-\gamma-\mathrm{Fe}_{2} \mathrm{O}_{3} \mathrm{NPs}$ were then washed with $\mathrm{ddH}_{2} \mathrm{O}(3 \times 10 \mathrm{~mL})$ using an Amicon ${ }^{\circ}$ Ultra-15 centrifugal filter device $(100 \mathrm{~K})$ operated at $4,000 \mathrm{rpm}$ for $5 \mathrm{~min}$ (at room temperature). This step was followed by a size exclusion step $(8,000 \mathrm{rpm}, 10 \mathrm{~min}$, at room temperature). The clean composite functional NPs were then re-dispersed in $\mathrm{ddH}_{2} \mathrm{O}(15 \mathrm{~mL})$ for storage $\left(2-8^{\circ} \mathrm{C}\right)$ and gene silencing experiments.

It is also worth noting that multiple other ratios of $b$-PEI $/$ PAMAM $_{\mathrm{G} 2}$ were tested as well. However, the chosen ratios mentioned above were found to be the optimal ones when tested as in vitro gene delivery systems.

The optimal types of composite functional nanocarriers (NCs) were also extensively characterized. The ${ }_{\text {inj }} \mathrm{PEI}_{25} / \mathrm{PAMAM}_{\mathrm{G} 2}-\mathrm{CAN}-\gamma$ $\mathrm{Fe}_{2} \mathrm{O}_{3}$ NPs average hydrodynamic diameter and $\zeta$ potential values were measured at $40.4 \pm 1.2 \mathrm{~nm}$ (Figure SI-1) and $+48.9 \pm 0.5 \mathrm{mV}$ respectively.

Magnetism features of the resulting NCs (SQUID measurements) and starting $\mathrm{CAN}-\gamma-\mathrm{Fe}_{2} \mathrm{O}_{3} \mathrm{NPs}$ confirm that corresponding functional NPs are indeed superparamagnetic (low values of coercive field) and therefore potentially useful for MRI (Figure 1). In contrast, the ${ }_{\text {inj }} \mathrm{PEI}_{25} /$ PAMAM $_{\mathrm{G}_{2}}-\mathrm{CAN}-\gamma-\mathrm{Fe}_{2} \mathrm{O}_{3} \mathrm{NPs}$ saturation magnetization $M s$ parameter had a value of $47.4 \mathrm{emu} / \mathrm{g}$ and a blocking temperature of $90.9-93.0^{\circ} \mathrm{K}$. The $M s$ value found is lower than the one measured for starting CAN$\gamma$ - $\mathrm{Fe}_{2} \mathrm{O}_{3} \mathrm{NPs}(59.48 \mathrm{emu} / \mathrm{g}$ ), [14] probably due to the respective weights of the non-magnetic polymer/organic species components of these functional NCs.

Then, elemental ICP-AES measurements were performed in order to determine the NCs elemental $\mathrm{Fe}$ and Ce concentrations of the resulting aqueous suspensions, which were 1.30 and $0.13 \mathrm{mg} /$ $\mathrm{mL}$ for both $\mathrm{Fe}$ and $\mathrm{Ce}$ elements $(\mathrm{Ce} / \mathrm{Fe}$ w/w ratio: 0.10$)$. Under similar fabrication conditions, basic polymer-free CAN- $\gamma-\mathrm{Fe}_{2} \mathrm{O}_{3} \mathrm{NPs}$ had a much lower $\mathrm{Ce} / \mathrm{Fe}$ w/w ratio of $0.029,[14]$ suggesting that the polymer/organic species types of the US-mediated NPs caused a significant increase in doping $\left[\mathrm{CeL}_{\mathrm{n}}\right]$ cation/complex amount, allowing future more effective use of coordination chemistry [11] for further functionalization developments.

Next, in order to have a better understanding of the corresponding decoration reaction mechanisms and the polymer/organic species binding onto the surface of [CeL $]$-doped maghemite NPs, XPS (Figure 2) and FTIR (Figure 3) analyses were conducted for both functional NCs.

XPS data disclose an $\mathrm{N}_{1 \mathrm{~s}}$ peak at a binding energy (BE) of 407.0 $\mathrm{eV}$ that can be attributed to Ce complexing nitrate ligands, since this binding energy value is typical of nitrate groups. This XPS $\mathrm{N}_{1 \mathrm{~s}}$ peak is the only one that also appears for starting CAN- $\gamma-\mathrm{Fe}_{2} \mathrm{O}_{3} \mathrm{NPs}$ [11]. Two other different XPS $\mathrm{N}_{1 \mathrm{~s}}$ peaks, which are typical of amine groups, were also found at binding energies of 399.5 and $402.0 \mathrm{eV}$. While the $402.0 \mathrm{eV}$ peak relates to both amine and ammonium groups, the other $399.5 \mathrm{eV} \mathrm{N}_{1 \mathrm{~s}}$ peak characterizes $\mathrm{N}$ atoms of $\mathrm{C}=\mathrm{N}$ (imine and imine derivatives) species together with amide ones. Next, $\mathrm{C}_{1 \mathrm{~s}}$ peak analysis enabled the characterization of (i) aliphatic carbons (BE: $285.0 \mathrm{eV}$ ), (ii) carbons that are bound to an oxygen atom (C-O, BE: $285.9 \mathrm{eV})$ and 
Citation: Israel LL, Lellouche E, Grenèche J, Bechor M, Michaeli S, et al. (2016) Ultrasound-Mediated Surface Engineering of Theranostic Magnetic Nanoparticles: An Effective One-Pot Functionalization Process Using Mixed Polymers for siRNA Delivery. J Nanomed Nanotechnol 7: 385. doi:10.4172/2157-7439.1000385
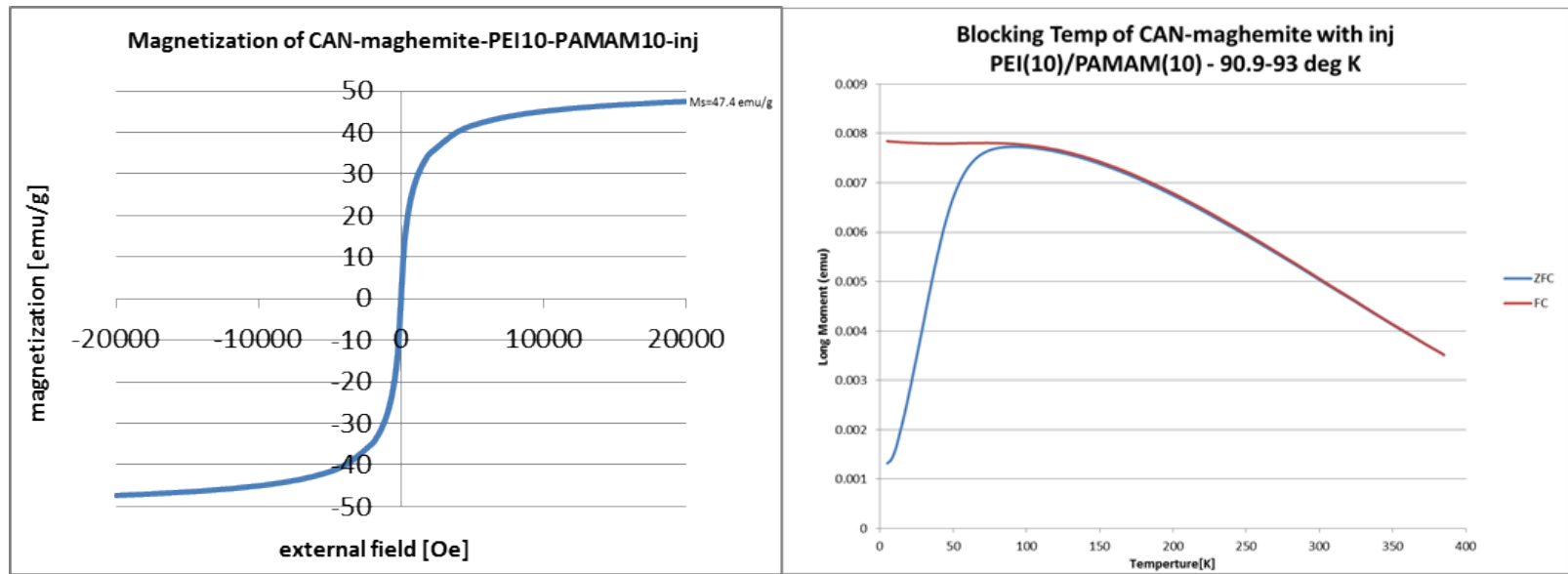

Figure 1: SQUID magnetization profile and ZFC/FC graphs of ${ }_{\text {inj }} \mathrm{PEI}_{25} / \mathrm{PAMAM} \mathrm{G}_{2}-\mathrm{CAN}-\gamma-\mathrm{Fe}_{2} \mathrm{O}_{3}$ (saturation magnetization $M s$ : 47.4 emu/g, blocking temperature $\left.\mathrm{T}_{\mathrm{B}}: 90.9-93^{\circ} \mathrm{K}, \mathrm{H}=100 \mathrm{Oe}\right)$.
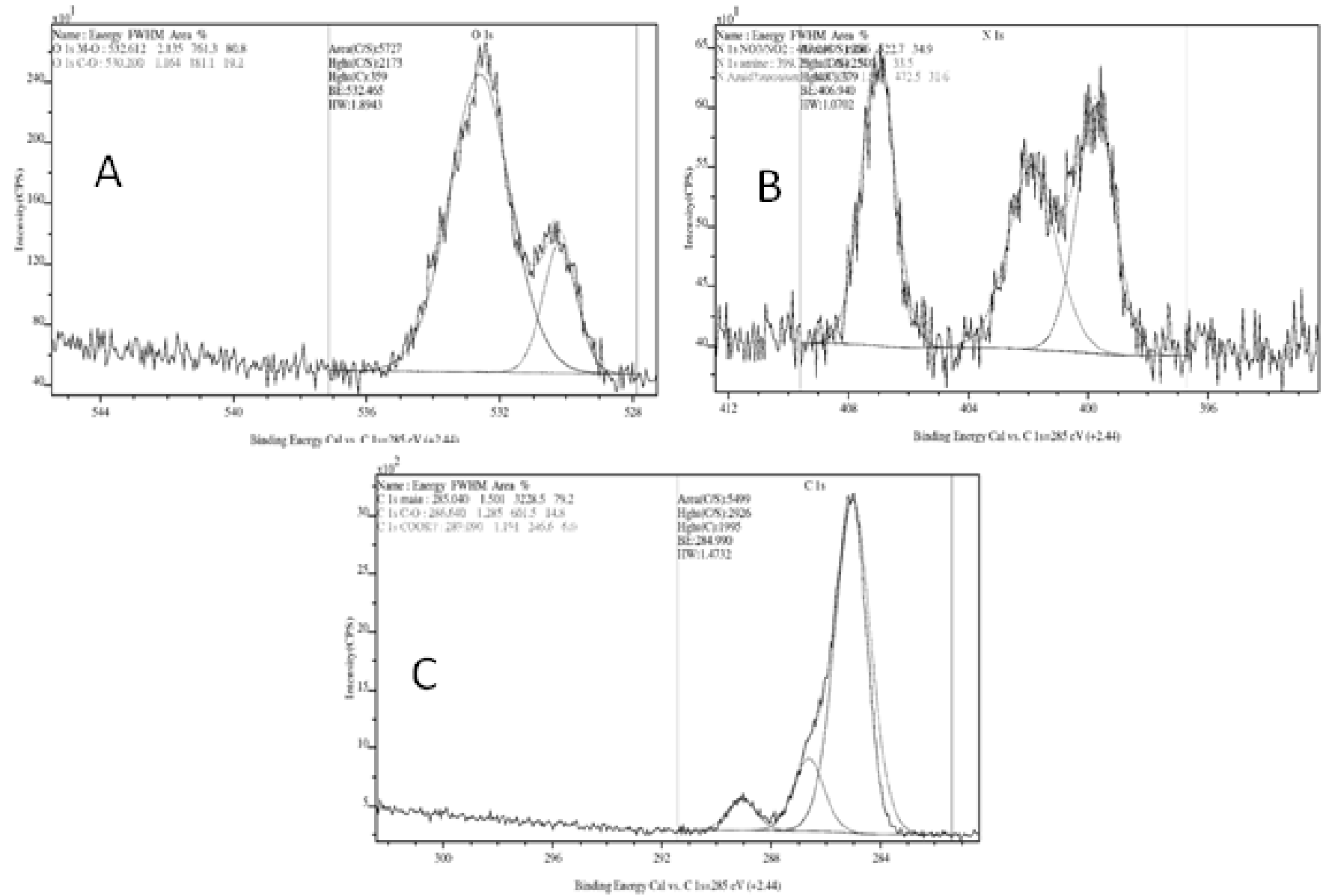

Figure 2: XPS spectroscopy of ${ }_{\text {inj }} \mathrm{PEI}_{25} / \mathrm{PAMAM}_{\mathrm{G} 2}-\mathrm{CAN}-\gamma-\mathrm{Fe}_{2} \mathrm{O}_{3}(\mathrm{~A}-\mathrm{C})$, where $A$ relates to $\mathrm{O}_{1 \mathrm{~s}}$ peaks, $\mathrm{B}$ to $\mathrm{N}_{1 \mathrm{~s}}$ peaks and $\mathrm{C}$ to $\mathrm{C}_{1 \mathrm{~s}}$ peaks.

(iii) carboxylic acid species (COOH, BE: $286.6 \mathrm{eV}$ ), including a specific $\mathrm{C}_{1 \mathrm{~s}}$ peak that may be attributed to carboxylic acid derivatives such as amides or esters groups (BE: $289.1 \mathrm{eV}$ ).

Two XPS $\mathrm{O}_{1 \mathrm{~s}}$ peaks have been also identified. One of them (BE: $532.4 \mathrm{eV}$ ) may be attributed to hydroxyl $(\mathrm{OH})$ species such as $\mathrm{Fe}-\mathrm{OH}$ and even nitrate groups, while the second one has a typical BE value of $\sim 530.2 \mathrm{eV}$ that characterizes a carboxylic acid O element.

The FTIR spectrum of the ${ }_{\text {inj }} \mathrm{PEI}_{25} / \mathrm{PAMAM}_{\mathrm{G} 2}-\mathrm{CAN}-\gamma-\mathrm{Fe}_{2} \mathrm{O}_{3} \mathrm{NPs}$ shows a broad peak at $3267-3686 \mathrm{~cm}$, which characterizes $\mathrm{O}-\mathrm{H}(\mathrm{Fe}-$ $\mathrm{OH}$ ) and both primary and secondary amine N-H stretching. Another 
Citation: Israel LL, Lellouche E, Grenèche J, Bechor M, Michaeli S, et al. (2016) Ultrasound-Mediated Surface Engineering of Theranostic Magnetic Nanoparticles: An Effective One-Pot Functionalization Process Using Mixed Polymers for siRNA Delivery. J Nanomed Nanotechnol 7: 385. doi:10.4172/2157-7439.1000385
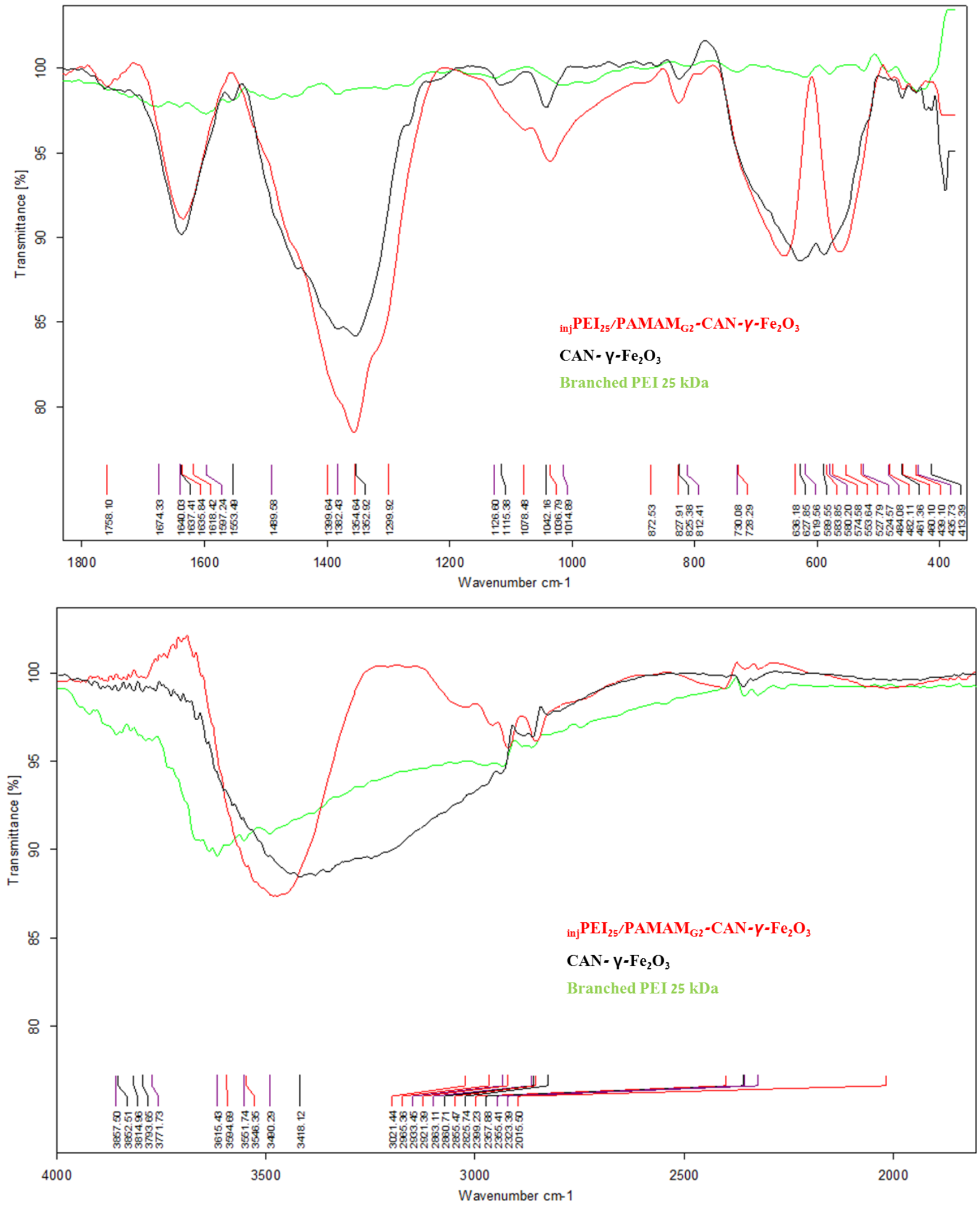

Figure 3: FTIR spectra of ${ }_{\text {inj }} \mathrm{PEI}_{25} / \mathrm{PAMAM}_{\mathrm{G} 2}-\mathrm{CAN}-\gamma-\mathrm{Fe}_{2} \mathrm{O}_{3} \mathrm{NPs}$ (red), $b-\mathrm{PEI}{ }_{25}$ (green) and $\mathrm{CAN}-\gamma-\mathrm{Fe}_{2} \mathrm{O}_{3} \mathrm{NPs}$ (CAN-maghemite, black). 
Citation: Israel LL, Lellouche E, Grenèche J, Bechor M, Michaeli S, et al. (2016) Ultrasound-Mediated Surface Engineering of Theranostic Magnetic Nanoparticles: An Effective One-Pot Functionalization Process Using Mixed Polymers for siRNA Delivery. J Nanomed Nanotechnol 7: 385. doi:10.4172/2157-7439.1000385

Page 8 of 14

broad envelope peak over the $2608-3267 \mathrm{~cm}$ range clearly contains multiple peaks. This envelope can be attributed to carboxylic acid $\mathrm{O}-\mathrm{H}$, alkane $\mathrm{C}-\mathrm{H}$ and aldehyde $\mathrm{C}-\mathrm{H}$ stretching. In addition, two small peaks appearing at 1756 and $1733 \mathrm{~cm}$ may be attributed to $\mathrm{C}=\mathrm{O}$ stretching of carboxylic acid and aldehyde groups, respectively. Another broad peak over the $1543-1690 \mathrm{~cm}$ range can be seen, with a main peak at 1636 $\mathrm{cm}$. This peak can be attributed to amine $\mathrm{N}-\mathrm{H}$ bending, imine $\mathrm{C}=\mathrm{N}$ or amide $\mathrm{C}=\mathrm{O}$ stretching. It may also relate to $\mathrm{C}=\mathrm{O}$ stretching of secondary amines present in the PAMAM structure. An even wider peak at 1218$1543 \mathrm{~cm}$ with a main peak at $1356 \mathrm{~cm}$ may also be attributed to $\mathrm{O}-\mathrm{H}$ bending of alcohols or carboxylic acids and C-H bending of alkane or aldehyde groups. Moreover, the $1037 \mathrm{~cm}$ peak can be attributed to amine $\mathrm{C}-\mathrm{N}$ and/or alcohol C-O stretching. Interestingly, as can be seen in the fingerprint areas of all NCs spectra, both characteristic 553.0 and $653.0 \mathrm{~cm}$ peaks may be attributed to $\mathrm{Fe}-\mathrm{O}$ bonds (core maghemite phase) and $\mathrm{C}-\mathrm{H}$ bending.

Considering the overall NPs doping process, these results can be explained by the radical-mediated ultrasound decomposition of the sole organic component used in the first step, the $\mathrm{MeCOMe}$ solvent. Scheme 2 illustrates the suggested mechanism of the $b-\mathrm{PEI}_{25}$ and PAMAM $\mathrm{G}_{2}$ attachment onto the NPs surface. Indeed, the main reaction intermediate steps involved in this aqueous oxidative USdriven process include (i) a first step of $\mathrm{H}$ radical $(\mathrm{H})$ abstraction by ultrasound-generated Fenton hydroxyl radicals $(\mathrm{OH})$ leading to ketoradicals 3, (ii) their corresponding radical re-combination or additional $\mathrm{CAN}$-mediated mono-electronic oxidation towards positively charged stabilized keto-cationic species 4 and (iii) obtaining $\mathrm{H}_{2} \mathrm{O}$-neutralized (nucleophilic addition) equilibrated (keto-enol equilibrium) hydroxylated species 1-hydroxypropan-2-one 5 and prop-1-ene-1,2diol 6. Finally, via trans-enolization, both species 5 and 6 react with NP surface amphoteric Fe(II/III)-OH groups to afford a NPs surface, chemically modified by a potentially CAN-oxidizable polyaldehyde (polyCHO) shell. As a direct result of the nucleophilic addition of amine NHR groups onto the aldehyde NP surface, further NP surface reactions may lead to Ce cation/complex-stabilized product A type imines (coordination chemistry). A further parallel CAN oxidation of existing polyCHO groups can probably lead to corresponding acidic product $\mathrm{B}$ type species (poly $\mathrm{COOH}$ shell) that may promote amide bond formation with NHR amine species under the existing high-power extreme ultrasonication conditions (obtaining the amide product type $\mathrm{C}$ species). Alternatively, a similar direct CAN-promoted radical generation of the $\mathrm{FeO}$ radical species $[39,40]$ from amphoteric $\mathrm{Fe}(\mathrm{II} / \mathrm{III})-\mathrm{OH}$ groups is possible. Such surface radicals may also fuel the corresponding radical polymerization of the former unsaturated species of the prop-1-ene-1,2-diol 6 type. Alternatively strong CAN oxidant may also directly oxidize the $b$ - $\mathrm{PEI}_{25}$ component to afford $b$ - $\mathrm{PEI}_{25}$-relating hydroxylamine species $(-\mathrm{NH}-\mathrm{OH})$ that may further react with polyCOOH and/or NPs surface $\mathrm{Fe}(\mathrm{II} / \mathrm{III})-\mathrm{OH}$ species for polymer phase binding.

In summary, any polymer/organic phase linking onto both ${ }_{\text {inj }} \mathrm{PEI}_{25} /$ PAMAM $_{\mathrm{G} 2}-\mathrm{CAN}-\gamma-\mathrm{Fe}_{2} \mathrm{O}_{3}$ NPs is clearly mediated by radical surface reactions promoted by high-power ultrasound energy in the presence of both MeCOMe and $\mathrm{H}_{2} \mathrm{O}$ components as ROS species generators [41] (Scheme 2). The resulting generated polyCOOH/polyOH shells enable provision of active chemical species for polyamine covalent conjugation. Interestingly, when the sole $b$ - $\mathrm{PEI}_{25}$ polymer was introduced into the reaction before starting the high-power ultrasonication (instead of being injected after 45 minutes of medium-level ultrasonication), its binding/attachment onto the NPs surface failed (checking by NPs DLS size and $\zeta$ potential measurements).

\section{In vitro and acute in vivo biology experiments using polymer- modified NCs}

First, a measurement of the siRNA adsorption by corresponding NCs was performed using a gel retardation assay (SI section, Figures SI-2 and SI-B). Briefly, both NPs suspensions were diluted in water at various concentrations to reach different $\mathrm{Fe} / \mathrm{siRNA} \mathrm{w} / \mathrm{w}$ ratios $(0.063,0.126,0.315,0.63,0.945$ and 1.26$)$. To each NPs suspension and control tube (C, absence of particles), $2 \mu \mathrm{g}$ of Firefly luciferase siRNA were added and incubated for $15 \mathrm{~min}$ at room temperature (RT) for the complex formation. After $15 \mathrm{~min}$ of incubation, the suspensions were loaded into $1.5 \%$ agarose gel that was pre-stained with ethidium bromide and electrophorized at $100 \mathrm{~mA}$ for $30 \mathrm{~min}$ in a tris-acetate (TAE) running buffer. The bands were visualized using a UV imaging system. The results of the assay clearly show siRNA adsorption at ratios between 0.315-1.26.

Next, in order to evaluate whether these NPs can efficiently silence genes, we used an efficient and reliable two-gene reporter system, based on the luciferase proteins of the $61 \mathrm{KDa}$ Firefly and $36 \mathrm{KDa}$ Renilla, which are expressed stably in human U2OS cells. This model enables the measurement of a specific silencing (Firefly), whereas the Renilla may remain unchanged unless the NPs induce toxicity, thereby causing cell death and reduction in the enzyme level compared to untreated cells (control). The Firefly luciferase silencing was conducted using a constant amount of the siRNA ( $100 \mathrm{nM}$, which is equal to $\sim 0.166 \mu \mathrm{g}$ of siRNA) that was mixed with ${ }_{\text {inj }} \mathrm{PEI}_{25} / \mathrm{PAMAM}_{\mathrm{G} 2}-\mathrm{CAN}-\gamma-\mathrm{Fe}_{2} \mathrm{O}_{3}$ (Figure 4A) NCs using the same separate $\mathrm{Fe} / \mathrm{siRNA}$ w/w ratios (0.63-5.04). Following the transfection with ${ }_{\text {inj }} \mathrm{PEI}_{25} / \mathrm{PAMAM}_{\mathrm{G} 2}-\mathrm{CAN}-\gamma-\mathrm{Fe}_{2} \mathrm{O}_{3}$ NPs, only the highest $\mathrm{Fe} / \mathrm{siRNA}$ w/w ratio obtained a significant and satisfying decrease of $73 \%$ with no sign of toxicity, since no changes in the Renilla levels were observed.

In addition to the in vitro experiments, due to the well-known acute in vivo toxicity of PEI polymers, we injected mice with both NCs in order to perform an initial evaluation of their acute in vivo toxicity. The mice were intravenously $(i v)$ injected with a dose of $1 \mathrm{mg} / \mathrm{kg}$ of RAC1 siRNA complexed with either ${ }_{\text {inj }} \mathrm{PEI}_{25}$ or $\mathrm{PAMAM}_{\mathrm{G} 2} \mathrm{CAN}-\boldsymbol{\gamma}-\mathrm{Fe}_{2} \mathrm{O}_{3} \mathrm{NCs}$ into the tail vein. Relying on observed Luciferase silencing in vitro results, the best Fe/siRNA w/w ratio (5.04) was used, for which the lowest necessary amount of iron (NPs) still yielded very efficient silencing without toxicity. Following $i v$ injection, neither mortality incidence nor any sign of mice distress were ever observed. For comparison, $b-\mathrm{PEI}_{25}$ $\mathrm{CAN}_{\mathrm{DOE}}-\gamma-\mathrm{Fe}_{2} \mathrm{O}_{3} \mathrm{NPs}$ (unmodified method A), which contain the same $b-\mathrm{PEI}_{25}$ polycationic phase coordinatively bound onto the same CAN $-\gamma-\mathrm{Fe}_{2} \mathrm{O}_{3}$ core (Ce cation/complex coordination chemistry, twostep fabrication process) for the same purpose (gene silencing), [11,34] have also been fabricated and injected into mice at the same $1 \mathrm{mg} / \mathrm{kg}$ dose (Fe/siRNA ratio of 0.315$)$. The injected mice were found dead two hours after the $i v$ injection, suggesting that both second polymer (G2 PAMAM) involvement and polymer/organic species attachment mode factors may strongly and positively influence acute in vivo toxicity of $b$ - $\mathrm{PEI}_{25}$-containing CAN- $\boldsymbol{\gamma}-\mathrm{Fe}_{2} \mathrm{O}_{3}$ NCs.

In addition to the sole $b$ - $\mathrm{PEI}_{25}$ (as mentioned above in the Introduction section), the same high-power US-mediated functional NCs fabrication protocol was tested with sole PAMAM dendrimers (G0-G3) at various NPs/organic weight/weight ratios. The resulting functional NCs were then tested in vitro using the same gene silencing system described above (Figure SI-3), displaying significantly lower effectiveness $(<45 \%)$ in terms of silencing capability, which is in some cases even more toxic than the whole set of NCs fabricated using combined $b$ - PEI $_{25} /$ PAMAM $_{\mathrm{G} 2}$ components. 
Citation: Israel LL, Lellouche E, Grenèche J, Bechor M, Michaeli S, et al. (2016) Ultrasound-Mediated Surface Engineering of Theranostic Magnetic Nanoparticles: An Effective One-Pot Functionalization Process Using Mixed Polymers for siRNA Delivery. J Nanomed Nanotechnol 7: 385. doi:10.4172/2157-7439.1000385

Page 9 of 14

A

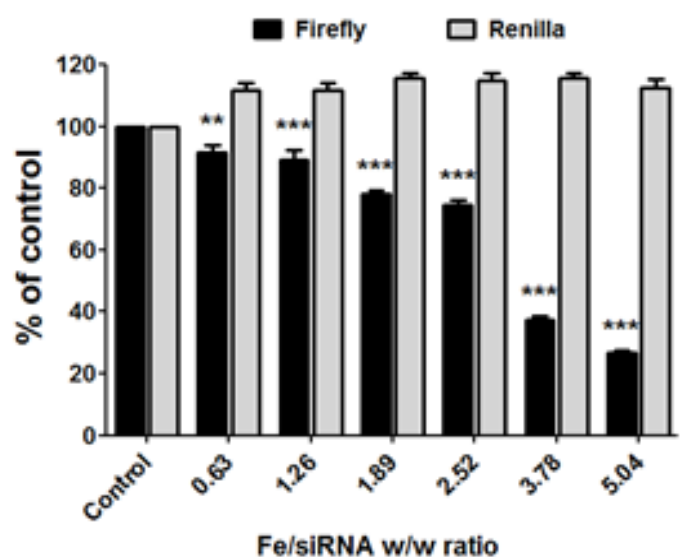

B

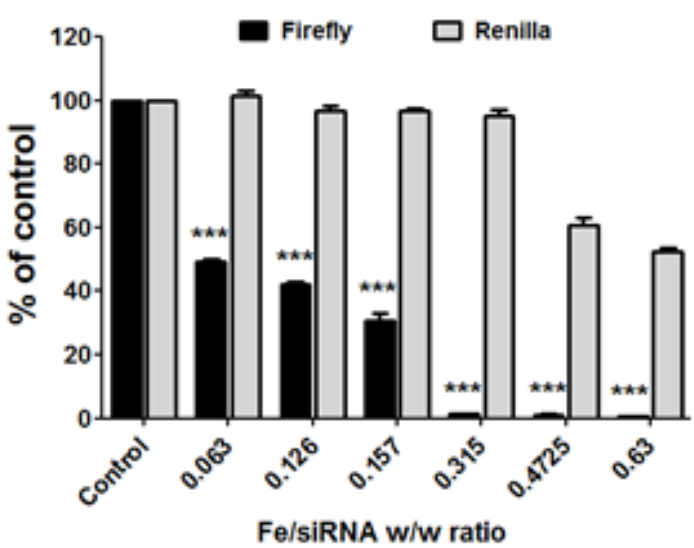

Figure 4: Luciferase silencing of ${ }_{\text {inj }} \mathrm{PEI}_{25} / \mathrm{PAMAM} \mathrm{G2}_{2}-\mathrm{CAN}-\gamma-\mathrm{Fe}_{2} \mathrm{O}_{3} \mathrm{NPs}$ using U2OS-Luc cells. U2OS-Luc cells (1x104 cells/well) were transfected with Firefly luciferase

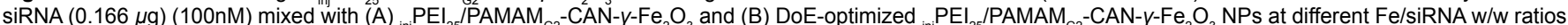
or without NPs (control). Forty-eight hours later, the cells were assayed for both Firefly and Renilla luciferase activities using the Dual-GLO Luciferase Assay System. Silencing efficacy is reflected by luciferase activities normalized to control luciferase activities. Data are expressed as mean \pm SEM of three different experiments according to the results of Two Way ANOVA with multiple comparison Bonferroni post hoc $\left({ }^{* *} \mathrm{p}<0.01,{ }^{* * *} \mathrm{p}<0.001 \mathrm{vs}\right.$. control Firefly).

\section{Global DoE-optimization of polymer-modified nanoscale delivery systems}

Encouraged by these positive results, a DoE process global optimization was performed in order to further improve these functional NCs and reduce the quantity of iron-based NPs needed for an effective silencing. A lower Fe/siRNA mass ratio, which stood at 5.04 for a maximal silencing percentage $(73 \%)$, was the starting point for this optimization process. In order to achieve this goal, a statistically designed set of experiments [42] (DoE) was planned.

This DoE study allows the change of more than one factor/reaction condition at a time even when multiple interacting factors are involved, and therefore fewer experiments are needed for the global optimization process. This approach also enables the study of which factors interact with each other and how these interactions may influence the final results, a strong processing advantage unavailable in a regular ofat (one factor at a time) optimization study. The experiments were designed using a statistical program (MINITAB version 16.2.4, Minitab Inc.), which generates a matrix of randomly set-up experimental runs, accounting for the critical factors of the chosen multi-parameter reaction.

For this purpose and based on our current process knowledge, four main factors that may affect this injection process were identified for globally optimized ${ }_{\text {inj }} \mathrm{PEI}_{25} / \mathrm{PAMAM}_{\mathrm{G} 2}-\mathrm{CAN}-\gamma-\mathrm{Fe}_{2} \mathrm{O}_{3}$ NC fabrication (Table 1).

Arranged at both low and high value levels, the investigated factors are (i) the CAN oxidant amount (the two low and high level values which were chosen: 75.0 and $125.0 \mathrm{mg}$ ), (ii) the volume of the $\mathrm{MeCOMe}$ solvent component at a total constant reaction $\mathrm{H}_{2} \mathrm{O} / \mathrm{MeCOMe}$ volume of $8.0 \mathrm{~mL}$ (the two low and high level values that were chosen: 2.0 and $6.0 \mathrm{~mL}$ ), (iii) the high-power ultrasonication time involved in the contact between the injected polymers and the iron oxide phase at fixed 25\% modulator power (Sonics ${ }^{\oplus}$, Vibra cell/Ti horn, 750 Watt; the two low and high level values which were chosen: the final 10 and 20 min times amongst a one hour total reaction time) and finally, (iv) the weight of the $b$ - $\mathrm{PEI}_{25}$ component out of a total organic species weight of $20.0 \mathrm{mg}$ for both the $b-\mathrm{PEI}_{25}$ and the PAMAM ${ }_{\mathrm{G} 2}$ components (the two low and high level values which were chosen: 5.0 and $15.0 \mathrm{mg}$ ).

\begin{tabular}{|c|c|c|c|c|c|c|c|}
\hline $\begin{array}{l}\text { Run } \\
\text { order }\end{array}$ & $\begin{array}{l}\text { CAN } \\
\text { (mg) }\end{array}$ & $\begin{array}{c}\text { MeCOMe } \\
x \text { mL/ } \\
\text { water=8 }\end{array}$ & $\begin{array}{c}\text { US } \\
\text { time } \\
\text { (min) }\end{array}$ & $\begin{array}{c}\text { PEI } \times \text { mg } \\
\text { (+PAMAM=20 } \\
\text { mg) }\end{array}$ & $\begin{array}{c}\text { Maximal } \\
\text { silencing } \\
(\%)\end{array}$ & $\begin{array}{c}\mathrm{Fe} / \\
\text { SiRNA at } \\
\text { maximal } \\
\text { silencing }\end{array}$ & $\begin{array}{c}\text { Fe con. } \\
\text { by ICP } \\
\text { (mg/ } \\
\text { mL) }\end{array}$ \\
\hline 1 & 75 & 2 & 20 & 5 & 50 & 2.52 & 0.44 \\
\hline 2 & 75 & 6 & 20 & 5 & 87 & 3.78 & 0.22 \\
\hline 3 & 125 & 2 & 20 & 15 & 92 & 5.04 & 1.50 \\
\hline 4 & 75 & 2 & 20 & 15 & 95 & 1.89 & 0.44 \\
\hline 5 & 125 & 6 & 20 & 5 & 43 & 3.78 & 1.15 \\
\hline 6 & 75 & 6 & 10 & 15 & 100 & 0.157 & 0.16 \\
\hline 7 & 75 & 2 & 10 & 15 & 100 & 1.26 & 0.29 \\
\hline 8 & 125 & 2 & 20 & 5 & 20 & 2.52 & 2.17 \\
\hline 9 & 125 & 2 & 10 & 15 & 80 & 5.04 & 2.00 \\
\hline 10 & 75 & 6 & 10 & 5 & 20 & 5.04 & 1.22 \\
\hline 11 & 125 & 6 & 10 & 15 & 66 & 3.78 & 1.79 \\
\hline 12 & 125 & 6 & 10 & 5 & 38 & 5.04 & 1.22 \\
\hline 13 & 125 & 6 & 20 & 15 & 90 & 5.04 & 1.42 \\
\hline 14 & 75 & 6 & 20 & 15 & 100 & 0.126 & 0.016 \\
\hline 15 & 100 & 4 & 15 & 10 & 95 & 5.04 & 1.90 \\
\hline 16 & 125 & 2 & 10 & 5 & 5 & 2.52 & 1.28 \\
\hline 17 & 75 & 2 & 10 & 5 & 72 & 5.04 & 0.34 \\
\hline
\end{tabular}

Table 1: Experimental array towards DoE-optimized ${ }_{\text {inj }} \mathrm{PEI}_{25} / \mathrm{PAMAM}_{\mathrm{G} 2}-\mathrm{CAN}-\gamma-$ $\mathrm{Fe}_{2} \mathrm{O}_{3} \mathrm{NPs}$ and corresponding process responses.

A four factor-two level full factorial experimental array was designed and analyzed using the MINITAB software with one factor replicate and one center point (Table 1, run order 15). This experimental array consists of 17 experiments, randomized in order to remove possible time-related confounding effects. The experiments provide quantified process responses including (i) the percentage of maximal silencing, (ii) the Fe/siRNA ratio at the point of maximal silencing and (iii) the final Fe concentration as measured by ICP-AES in order to get a precise indication of the final reaction yield (Table 1).

Table 1 reveals clear improvement in the Fe/siRNA ratio in some of the effective runs (mainly 6 and 14). However, using software statistical tools, an even deeper analysis of the obtained data was performed, which provided a better understanding of the overall reaction mechanism and its critical factors. The Pareto chart shown in Figure 5 is an example 
Citation: Israel LL, Lellouche E, Grenèche J, Bechor M, Michaeli S, et al. (2016) Ultrasound-Mediated Surface Engineering of Theranostic Magnetic Nanoparticles: An Effective One-Pot Functionalization Process Using Mixed Polymers for siRNA Delivery. J Nanomed Nanotechnol 7: 385. doi:10.4172/2157-7439.1000385
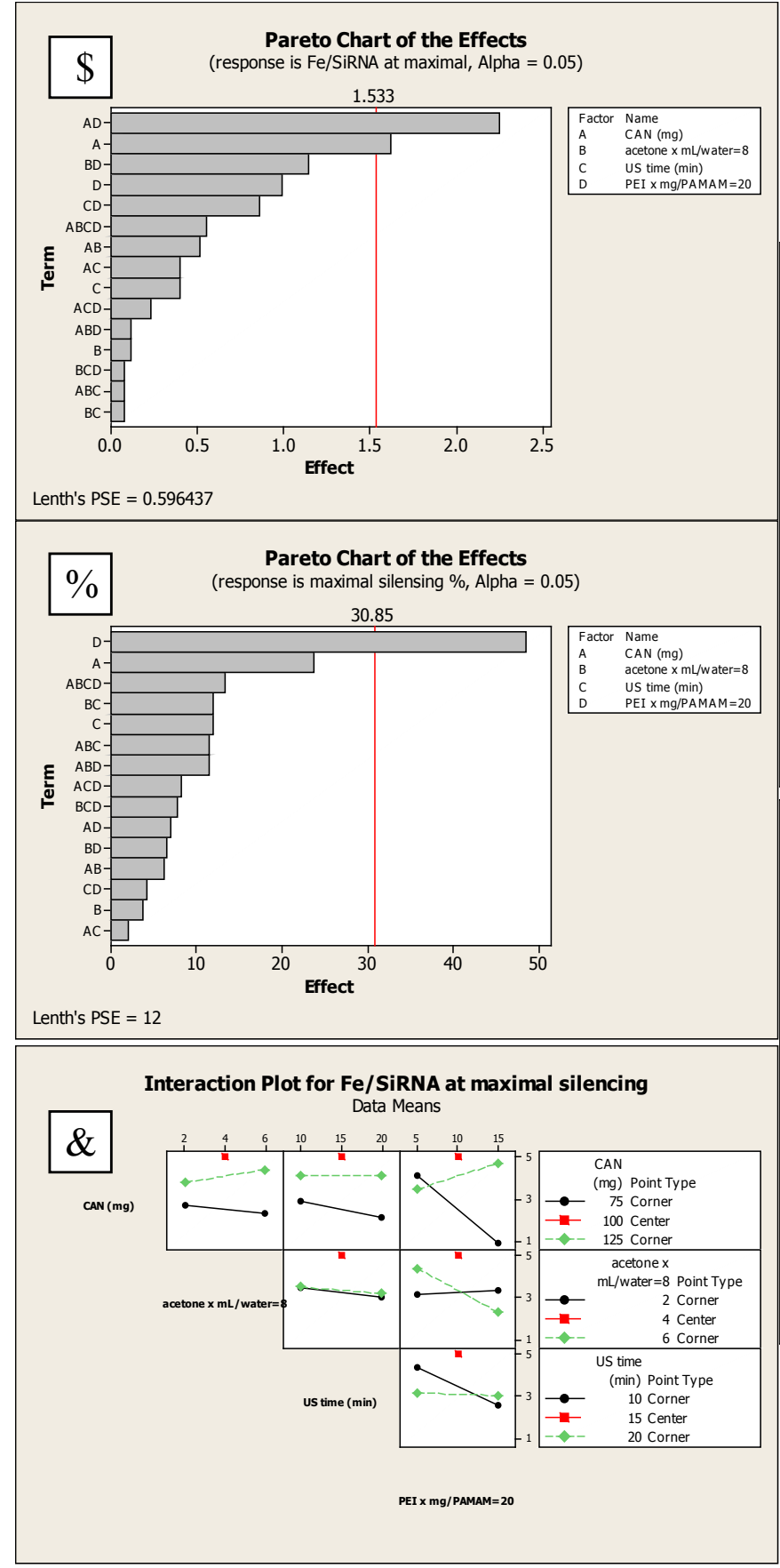

Figure 5: (A) Pareto chart of standardized effects for the responses of Fe/SiRNA ratio at maximal silencing, (B) percent of maximal silencing, (C) full interaction plot matrices for Fe/SiRNA ratio at maximal silencing, (D) 2D contour plot of Fe concentration by ICP-AES vs. CAN oxidant (mg) and PEI (mg, out of a total of 20 mg polymers) amounts and (E) Fe/SiRNA ratio at maximal silencing vs. CAN oxidant (mg) and PEI (mg, out of a total of $20 \mathrm{mg}$ polymers) amounts for ${ }_{\text {inj }} \mathrm{PEI}_{25} / \mathrm{PAMAM}_{\mathrm{G} 2}{ }^{-}$ $\mathrm{CAN}-\gamma-\mathrm{Fe}_{2} \mathrm{O}_{3} \mathrm{NPs}$.

of such an analysis, which displays the most significant factors for a certain given response. For example, it shows that the most important factor influencing the percentage of maximal silencing is the $b-\mathrm{PEI}_{25} /$ PAMAM $_{\mathrm{G} 2}$ weight ratio, since it is the only red line-crossing factor and therefore statistically significant. However, the most important factors that influence the Fe/siRNA ratio parameter that is needed for maximal gene silencing are the interaction between the amounts of CAN oxidant
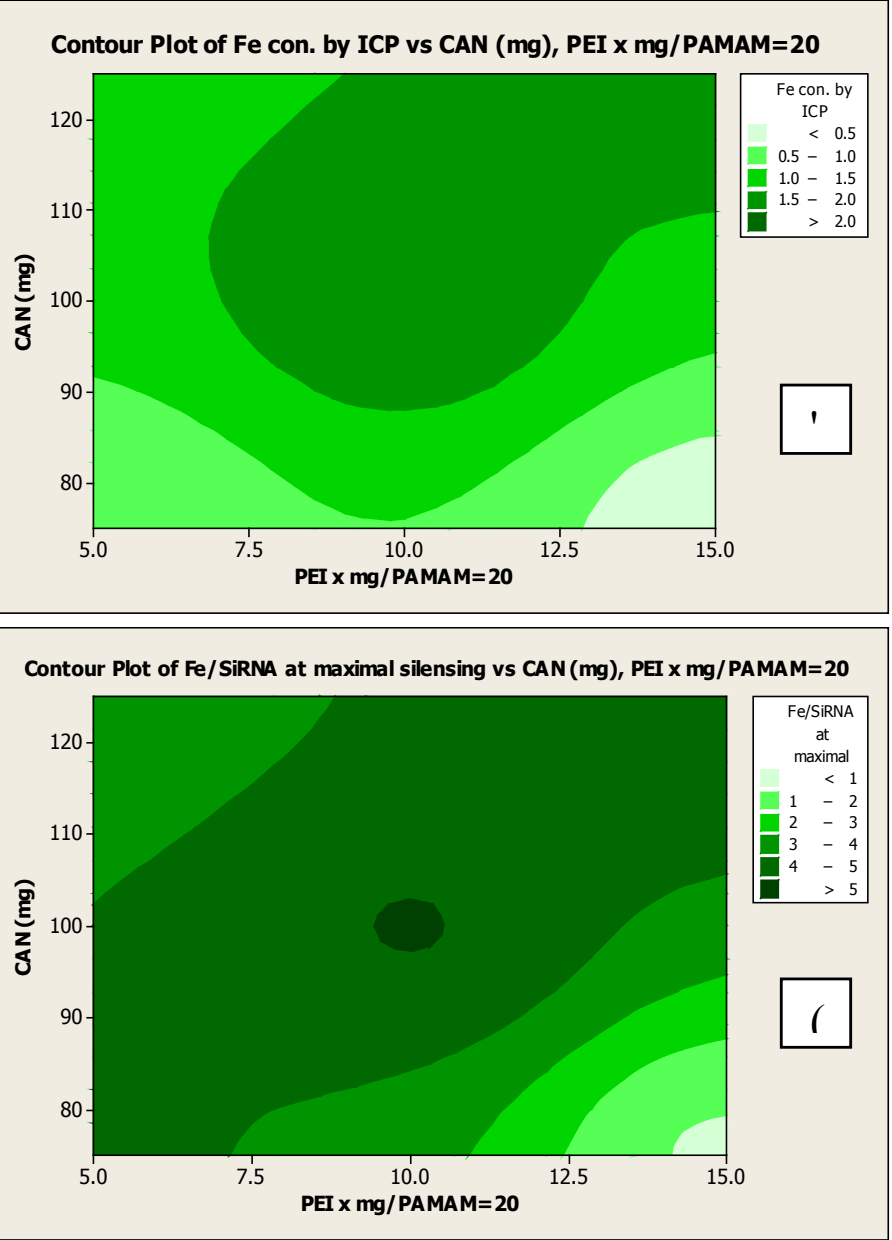

and $b$ - $\mathrm{PEI}_{25} / \mathrm{PAMAM}_{\mathrm{G} 2}$ weight ratio, and the amount of CAN oxidant itself (Figure 5). The strong interaction between the CAN oxidant and the polymer ratio component is also clearly shown in the interaction plot in Figure 5C. Such an interaction plot shows whether there is interaction between two different factors/reaction conditions for a given response. In Figure 5C, the response analyzed is the Fe/SiRNA ratio at maximal gene silencing. When two of the graphs correspond 
Citation: Israel LL, Lellouche E, Grenèche J, Bechor M, Michaeli S, et al. (2016) Ultrasound-Mediated Surface Engineering of Theranostic Magnetic Nanoparticles: An Effective One-Pot Functionalization Process Using Mixed Polymers for siRNA Delivery. J Nanomed Nanotechnol 7: 385. doi:10.4172/2157-7439.1000385

(for example, the MeCOMe $\mathrm{X} \mathrm{mL} /$ water and the US time, Figure $5 \mathrm{C}$ middle left), it indicates that there is no interaction between these two factors. However, when the two graphs are significantly different and even cross each other (for example, the MeCOMe volume $[\mathrm{X} \mathrm{mL} /$ water] and the $b-\mathrm{PEI}_{25} / \mathrm{PAMAM}_{\mathrm{G} 2}$ ratio $[\mathrm{x} \mathrm{mg} / \mathrm{PAMAM}=20]$, Figure $5 \mathrm{C}$ middle right), it implies a strong interaction between these two factors. This means that a change in one of the factors leads to a change in the other one, implying that the two factors/reaction conditions are interdependent. More moderate factor interactions can be detected between the polymer ratio and the $\mathrm{MeCOMe}$ volume and between the polymer ratio and sonication time (Figure 5C).

An example of a different kind of analysis (contour plot) is shown in Figure 5E. In this graphical analysis, as in a topographic map, two of the factors are shown in the $\mathrm{X}$ and $\mathrm{Y}$-axes, while the chosen response is color-coded in the Z-axis.

As seen in the contour plot presented in Figure 5E, the worst conditions for the Fe/siRNA ratio response are at the center point of the design, representing the conditions of the original starting reaction. Any shift from these conditions will improve the original output for this response, although the optimal conditions are found near the endpoints. The optimal conditions for this response, however, are not optimal for the Fe concentration response, which emphasizes the reaction yield (Figure 5D).

Following an extensive analysis, an optimal setting of reaction conditions was needed. For this purpose, the MINITAB 16 software profile optimizer tool was used, with the following specifications (Figure SI-4): the percentage of maximal silencing was targeted at 100\% with a lower limit of $70 \%$, the ratio of $\mathrm{Fe} / \mathrm{siRNA}$ at maximal silencing was targeted at 0.3 with an upper limit of 0.8 and the Fe concentration was targeted at $1.2 \mathrm{mg} / \mathrm{mL}$ with a lower limit of $0.4 \mathrm{mg} / \mathrm{mL}$. The importance of all three responses was defined as equal and set at value one (when it is not equal, a maximum of 10 and a minimum of 1 can be set, the higher the value of the importance factor, the more important the response).

The corresponding optimization plot is reported in Figure 6 (red data/red current line), which shows the effect of each factor (columns) on the corresponding responses and the response desirability (right column, blue data). In this case, the software optimizer tool suggested the use of a CAN quantity of $81.57 \mathrm{mg}, 6.0 \mathrm{~mL}$ of MeCOMe (out of a total of $8.0 \mathrm{~mL}$, which means $2.0 \mathrm{~mL}$ of $\mathrm{H}_{2} \mathrm{O}$ ), 10 minutes of ultrasonication with injected polymers/organic species and $15.0 \mathrm{mg}$ of the $b-\mathrm{PEI}_{25}$ component (out of $20.0 \mathrm{mg}$ polymers in total, which means $5.0 \mathrm{mg}$ of G2 PAMAM).

The corresponding functional NPs were then fabricated according to the conditions calculated with the optimizer tool, followed by the full characterization of the resulting functional nanosystem. The hydrodynamic diameter and the $\zeta$ potential of the DoE-optimized NPs calculated were $110.6 \pm 1.7 \mathrm{~nm}$ and $+41.7 \pm 1.9 \mathrm{mV}$, respectively, indicating a large increase in the NP hydrodynamic diameter compared to former pre-DoE NPs. Both $\mathrm{Fe}$ and $\mathrm{Ce}$ measurements by ICPAES were performed for their resulting cleaned aqueous dispersion. Surprisingly, the amount of Ce calculated was even higher than the amount of $\mathrm{Fe}$, with values of $\mathrm{Ce}=0.769 \mathrm{mg} / \mathrm{mL}$ and $\mathrm{Fe}=0.737 \mathrm{mg} / \mathrm{mL}$, giving a final $\mathrm{w} / \mathrm{w} \mathrm{Ce} / \mathrm{Fe}$ ratio of 1.04. TEM and HR-TEM images of the DoE-optimized nanosystem can be seen in Figure 7. Round crystalline particles can be seen in both images, although it is difficult to see all of the fringes in the HR-TEM microphotograph (Figure 7) because of the presence of the polymeric shell. A NPs-sized distribution by TEM

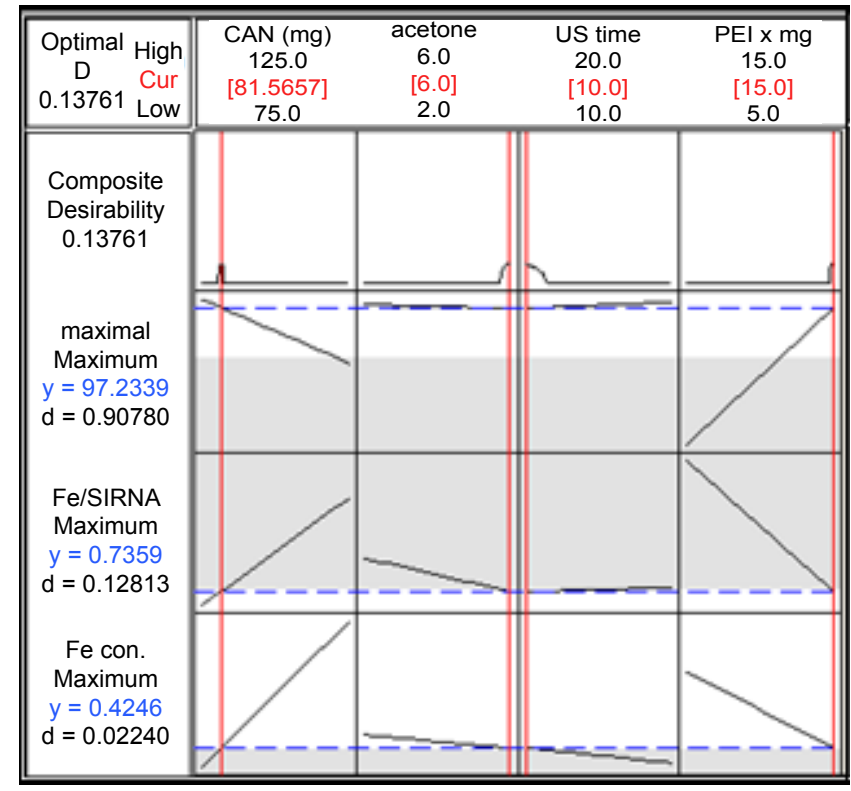

Figure 6: Calculated optimization plot (red data/red current line) using the MINITAB $^{\circledR} 1617$ software profile optimizer tool for ${ }_{\text {inj }}$ PEI $_{25} /$ PAMAM $_{G 2}-\mathrm{CAN}-\gamma-$ $\mathrm{Fe}_{2} \mathrm{O}_{3} \mathrm{NPS}$.

was also measured (more than 100 objects), leading to an average value of $6.35 \pm 1.50 \mathrm{~nm}$ (Figure 7). Also, the SAED pattern in Figure 7 confirms the reverse spinel crystal structure of the maghemite species, while an EDAX analysis (Figure SI-5) confirms ICP findings showing a higher weight percentage of $\mathrm{Ce}(42.1 \%)$ than that of $\mathrm{Fe}(38.8 \%)$. In addition, a high atomic percentage of $\mathrm{O}(19.1 \%)$ is also evident. This can be explained by an increase in the polymer binding effectiveness in such a DoE global optimization process. Thermal Gravimetric Analysis (TGA) was also performed for the ${ }_{\text {inj }} \mathrm{PEI}_{25} / \mathrm{PAMAM}_{\mathrm{G} 2}-\mathrm{CAN}-\gamma-\mathrm{Fe}_{2} \mathrm{O}_{3}$ NCs before and after the DoE global optimization (Figure 7). Before the optimization, the total weight loss observed over the temperature range of $100-800^{\circ} \mathrm{C}$ was $36.17 \%$, where two main steps are clearly shown by the derivative function over the temperature ranges of 100 $198^{\circ} \mathrm{C}$ and $198-247^{\circ} \mathrm{C}$. After the DoE global optimization, the total weight loss over the same temperature range $\left(100-800^{\circ} \mathrm{C}\right)$ was $80.11 \%$ with a large increase in the second step weight loss (from a percentage of $7.35 \%$ before the optimization to a $35.59 \%$ percentage after the optimization). In addition, an increase was also seen in the third step (which can again be divided into three mini-steps according to the first derivative function). The observed increase in the amount of polymer can probably cause a reinforced uptake of Ce cations/complexes by imine stabilization/coordination, for example, together with the simple complexion of Ce cations/complexes by the $b-\mathrm{PEI}_{25}$ and $\mathrm{PAMAM}_{\mathrm{G} 2}$ amine groups. Since some of the $\mathrm{CAN}$-originating nitrate ligands remain linked to the NP surface, an increased quantity of elemental O is clearly observed. Elemental analysis of such DoE-optimized ${ }_{\text {inj }} \mathrm{PEI}_{25} /$ PAMAM $_{\mathrm{G} 2}-\mathrm{CAN}-\gamma$ - $\mathrm{Fe}_{2} \mathrm{O}_{3} \mathrm{NPs}$ was also performed and resulted in $17.96 \%$ nitrogen, $19.38 \%$ carbon and $4.98 \%$ hydrogen. Interestingly, when a similar DoE study was performed for global optimization of the starting core CAN- $\gamma-\mathrm{Fe}_{2} \mathrm{O}_{3} \mathrm{NPs}$ (without polymer grafting), the optimal conditions found required more $\mathrm{H}_{2} \mathrm{O}$ than the MeCOMe in order to increase the Ce cation/complex doping onto the NP surface. Carboxylic acid groups were detected on core non-grafted CAN- $\gamma$ $\mathrm{Fe}_{2} \mathrm{O}_{3}$ NPs by FTIR, and XPS analysis was quantified by the Kaiser test $[43,44]$ at a $0.023 \mathrm{mmol} / \mathrm{g}$ NP value.[11,17,35] For the current DoE- 
Citation: Israel LL, Lellouche E, Grenèche J, Bechor M, Michaeli S, et al. (2016) Ultrasound-Mediated Surface Engineering of Theranostic Magnetic Nanoparticles: An Effective One-Pot Functionalization Process Using Mixed Polymers for siRNA Delivery. J Nanomed Nanotechnol 7: 385. doi:10.4172/2157-7439.1000385
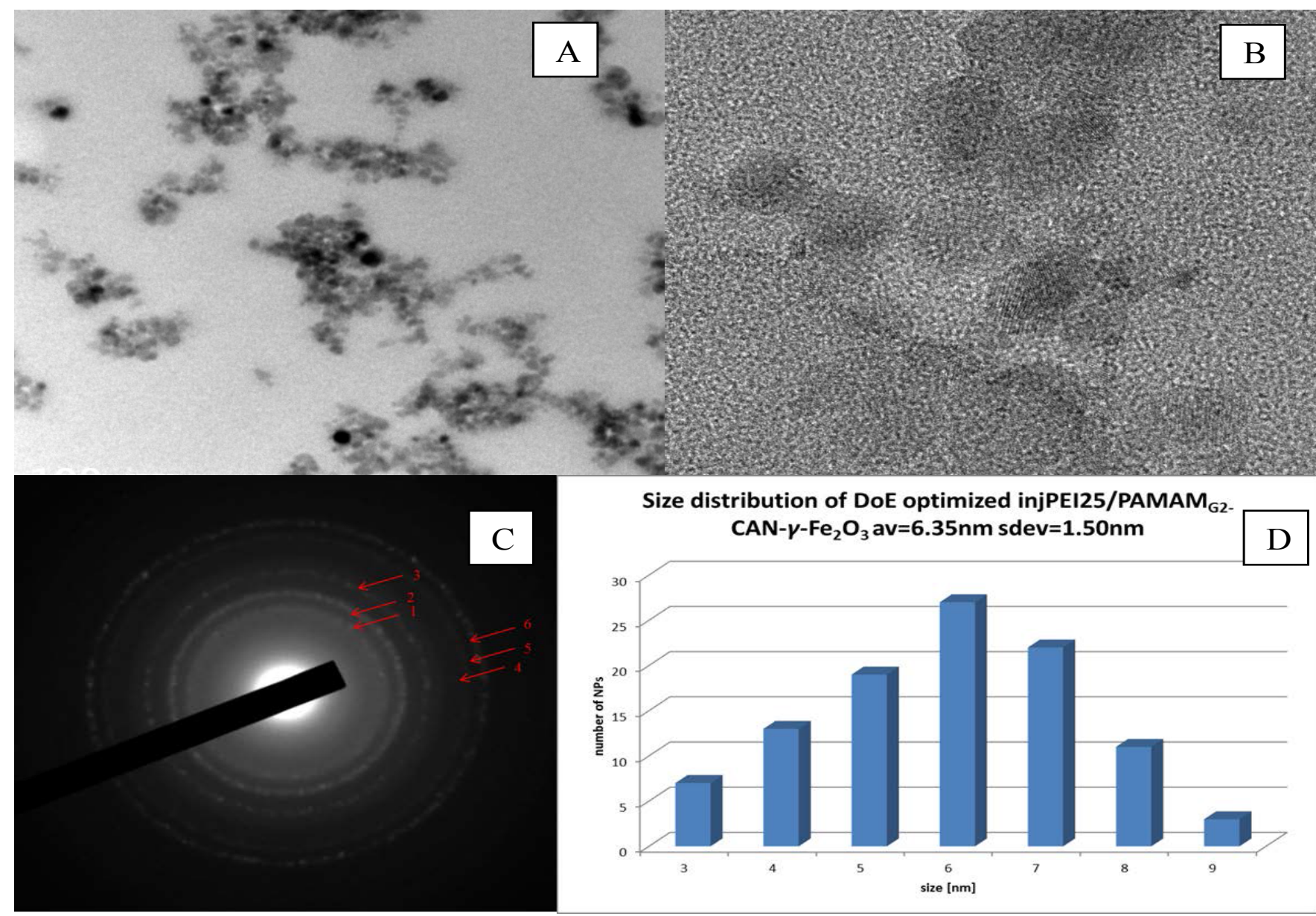

Size distribution of DoE optimized injPEI25/PAMAM ${ }_{\mathrm{G} 2}$

$\mathrm{CAN}-\gamma-\mathrm{Fe}_{2} \mathrm{O}_{3}$ av $=6.35 \mathrm{~nm}$ sdev $=1.50 \mathrm{~nm}$

$\mathrm{D}$
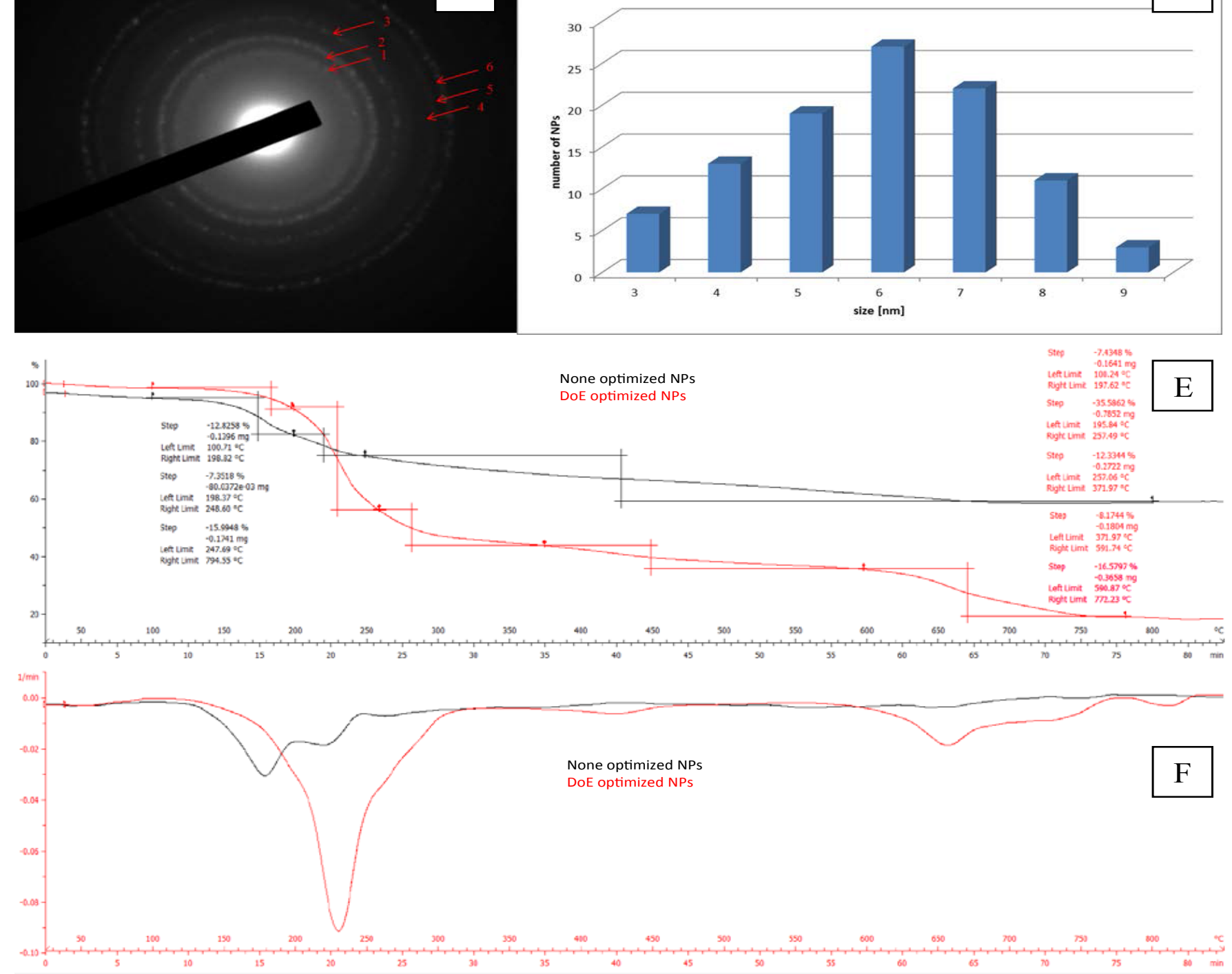

Figure 7: DoE-optimized $\mathrm{PEI}_{25} / \mathrm{PAMAM}_{\mathrm{G} 2}-\mathrm{CAN}-\gamma-\mathrm{Fe}_{2} \mathrm{O}_{3} \mathrm{NPs}-(\mathrm{A}) \mathrm{TEM}$ (scale bar: $100 \mathrm{~nm}$ ) and (B) HR-TEM (scale bar: $5 \mathrm{~nm}$ ) microphotographs with (C) HR-TEM/ selected area electron diffraction (SAED) patterns: \#1 (plane 220), \#2 (plane 311), \#3 (plane 400) and \#6 (plane 440), (D) size distribution by TEM and (E) TGA thermogram together with $(F)$ weight loss derivative function graphs. 
Citation: Israel LL, Lellouche E, Grenèche J, Bechor M, Michaeli S, et al. (2016) Ultrasound-Mediated Surface Engineering of Theranostic Magnetic Nanoparticles: An Effective One-Pot Functionalization Process Using Mixed Polymers for siRNA Delivery. J Nanomed Nanotechnol 7: 385. doi:10.4172/2157-7439.1000385

Page 13 of 14

optimized ${ }_{\text {inj }} \mathrm{PEI}_{25} / \mathrm{PAMAM}_{\mathrm{G} 2}-\mathrm{CAN}-\gamma-\mathrm{Fe}_{2} \mathrm{O}_{3} \mathrm{NCs}$, the same Kaiser test was also performed, resulting in a value of $0.185 \mathrm{mmol} / \mathrm{g}$ NPs [11]. This result strongly supports the suggested mechanism of MeCOMemediated involvement because of the carboxylic acid groups detected on the core NPs and the reaction conditions needed to reinforce the Ce cation/complex NP surface doping (more $\mathrm{H}_{2} \mathrm{O}$ than $\mathrm{MeCOMe}$ ), which are the opposite of those needed to reinforce the surface polymer/ organic amounts (more MeCOMe than $\mathrm{H}_{2} \mathrm{O}$ ).

In addition, both CAN-maghemite and DoE-optimized ${ }_{\text {ini }} \mathrm{PEI}_{25} /$ PAMAM $_{\mathrm{G}_{2}}-\mathrm{CAN}-\boldsymbol{\gamma}-\mathrm{Fe}_{2} \mathrm{O}_{3} \mathrm{NCs}$ were characterized using Fe Mössbauer spectrometry at $77^{\circ} \mathrm{K}$ (Figure 8). Their hyperfine structures, which result from magnetic well-resolved sextets with broadened and asymmetrical lines have to be described by means of discrete distributions of hyperfine field linearly convoluted with that of isomer shifts. The first conclusion arose from the mean values of isomer shift $(0.43 \mathrm{~mm} / \mathrm{s})$ that are typical of the presence of sole ferric Fe species which are tetrahedrally and octahedrally coordinated, as expected in the case of maghemite NPs. This indicates that the polymer US-mediated injection process does not initiate nor modulate any electron transfer. In addition, the hyperfine field distribution characteristic of such as-prepared NPs is consistent with the presence of slow relaxation superparamagnetism phenomena. After injection of mixed PEI/PAMAM species, the hyperfine field distribution becomes in one way narrower, suggesting a tendency towards a static magnetic behavior, and in another way a low field contribution, thus suggesting also an increase of the presence of USrelating dynamic effects. One should conclude that this US-mediated injection process gives rise to magnetically blocked non-interacting nanoparticles.

\section{In vitro and acute in vivo biology tests of the DoE optimized nano-systems}

After ${ }_{\text {inj }} \mathrm{PEI}_{25} / \mathrm{PAMAM}_{\mathrm{G} 2}$-CAN- $\gamma$ - $\mathrm{Fe}_{2} \mathrm{O}_{3}$ was DoE-optimized and characterized some additional in vitro tests were performed (Figure

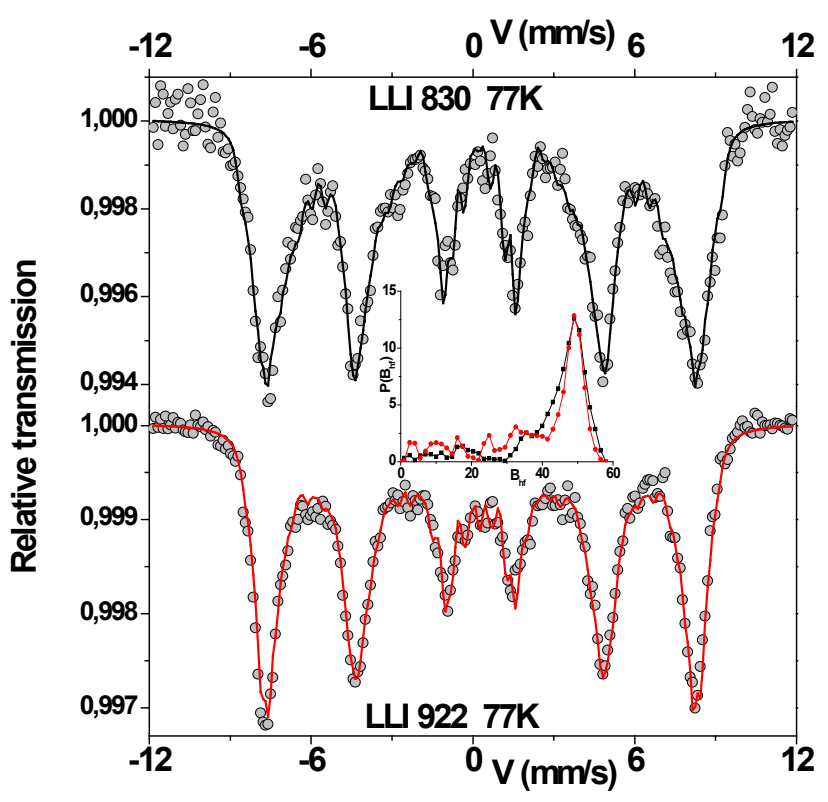

Figure 8: ${ }^{57} \mathrm{Fe}$ Mössbauer spectrometry of CAN-maghemite (LLI 830, top) and DoE-optimized $\mathrm{PEI}_{25} / \mathrm{PAMAM}_{{ }_{2}}-\mathrm{CAN}-\gamma-\mathrm{Fe}_{2} \mathrm{O}_{3} \mathrm{NCs}$ (LLI 922, bottom); the hyperfine field distributions are also compared at the center (black and red correspond to $1^{\text {st }}$ and $2^{\text {nd }}$ sample respectively).
$4 \mathrm{~b})$. First, the siRNA adsorption of both DoE-optimized nano-systems was reevaluated (Figure SI-7). For ${ }_{\text {inj }} \mathrm{PEI}_{25} / \mathrm{PAMAM}_{\mathrm{G} 2}-\mathrm{CAN}-\gamma-\mathrm{Fe}_{2} \mathrm{O}_{3}$, a very significant improvement was achieved and siRNA adsorption reached a very low Fe/siRNA ratio of 0.063 . This significant increase in the siRNA adsorption capability of the ${ }_{\text {inj }} \mathrm{PEI}_{25} / \mathrm{PAMAM}_{\mathrm{G} 2}-\mathrm{CAN}-\gamma$ $\mathrm{Fe}_{2} \mathrm{O}_{3} \mathrm{NPs}$ can be explained by the large increase in the surface polymer amounts, as detected and quantified by TGA (see above). Therefore, when the in vitro silencing was measured for the ${ }_{\text {inj }} \mathrm{PEI}_{25} / \mathrm{PAMAM}_{\mathrm{G} 2}$ CAN- $\gamma$ - $\mathrm{Fe}_{2} \mathrm{O}_{3}$ NPs after the global DoE optimization described below, a drastic increment in gene silencing efficacy was observed. As shown in Figure 4b, the transfection of the U2OS-Luc cells with the globally DoE-optimized NCs led to a significant silencing value of $98 \%(\mathrm{Fe} /$ siRNA w/w ratio of 0.315 ) with no sign of toxicity, since a change in the Renilla levels was not obtained. These results imply an improvement in the effectiveness of the DoE-optimized ${ }_{\text {inj }} \mathrm{PEI}_{25} / \mathrm{PAMAM}_{\mathrm{G} 2}-\mathrm{CAN}-\boldsymbol{\gamma}-\mathrm{Fe}_{2} \mathrm{O}_{3} \mathrm{NPs}$ by factors of sixteen (Fe/siRNA w/w ratios of 0.315 instead 5.04).

Following the positive results achieved when testing in vitro gene silencing, the DoE-optimized nanosystem was injected into mice, as previously done for the non-optimized NCs. However, for the in vivo testing, the best $\mathrm{Fe} / \mathrm{siRNA}$ w/w ratio, 0.315, was used. Interestingly, no animal deaths were observed after the $i v$ injections, suggesting that the system can be useful for future dual imaging/therapy nanoscale agents for siRNA delivery and therapy.

\section{Conclusion}

Superparamagnetic DoE-optimized ${ }_{\text {inj }} \mathrm{PEI}_{25} / \mathrm{PAMAM}_{\mathrm{G} 2}-\mathrm{CAN}$ $\gamma$ - $\mathrm{Fe}_{2} \mathrm{O}_{3}$ NPs combine an attractive $T_{2}^{*}$ potential MRI contrast effect (maghemite phase) and a very effective siRNA complexation for cell transfection without any observed acute in vivo toxicity. DoE global optimization studies significantly improved NP effectiveness in siRNA delivery and provided a deeper understanding of how selected reaction factors promote the suggested polymer/organic species grafting mechanism onto the NPs surface. This unique high-power ultrasoundmediated NP fabrication/surface engineering protocol did not make use of any common bifunctional conjugating agent for second step functionalization. It afforded a superparamagnetic maghemite core NPs surface-engineered with variable polymer/organic species coatings as a versatile surface functionalization platform that may strongly fuel further second step functionalization in future bio-applications. For example, for any corresponding mode of NP functionalization/surface engineering, NPs surface doping by $\left[\mathrm{CeL}_{\mathrm{n}}\right]$ cations/complexes may also be readily exploited as an additional parallel inorganic binding platform for organic ligands/species (tumor targeting species), as previously demonstrated [11]. In addition, the high amount of carboxylic acids on the surface that was quantified by the Kaiser test provides an additional (and orthogonal) route to further functionalizing this system in the future, such as targeting moieties.

\section{Supporting Information}

The Supporting Information contains additional experimental procedures, characterization data and figures.

\section{Acknowledgements}

We warmly acknowledge the funding for this R\&D work, which was provided by (i) the VII Framework RTD European Project (FP7-NMP-2010-LARGE-4 area) - Large Collaborative Project SaveMe (grant agreement $n^{\circ} 263307$ ) and (ii) the Israel Ministry of Trade and Industry, - "RIMONIM" project. All the authors also acknowledge Mrs. Ella Kurlander (Prof. Michaeli' s team) for her help in siRNA adsorption experiments. 
Citation: Israel LL, Lellouche E, Grenèche J, Bechor M, Michaeli S, et al. (2016) Ultrasound-Mediated Surface Engineering of Theranostic Magnetic Nanoparticles: An Effective One-Pot Functionalization Process Using Mixed Polymers for siRNA Delivery. J Nanomed Nanotechnol 7: 385. doi:10.4172/2157-7439.1000385

Page 14 of 14

\section{References}

1. Caruso F, Hyeon T, Rotello VM (2012) Nanomedicine. Chem Soc Rev 4 2537-2538.

2. Doane TL, Burda C (2012) The unique role of nanoparticles in nanomedicine: imaging, drug delivery and therapy. Chem Soc Rev 4: 2885-29.

3. Ling D, Hyeon T (2013) Chemical Design of Biocompatible Iron Oxide Nanoparticles for Medical Applications. Small 9: 450-466

4. Huber DL (2005) Synthesis, properties, and applications of iron nanoparticles $482-450$

5. Silva AC, Oliveira TR, Mamani JB, Malheiros SMF, Malavolta L, et al. (2011) Application of hyperthermia induced by superparamagnetic iron oxide nanoparticles in glioma treatment. International Journal of Nanomedicine 20: 6-59.

6. Grootendorst DJ, Jose J, Ratila RM, Visscher M, Velders AH, et al. (2012) Evaluation of superparamagnetic iron oxide nanoparticles (Endorem ${ }^{\circledR}$ ) as photoacoustic contrast agent for intra-operative nodal staging. Contrast Media \& Molecular Imaging 8: 83-9.

7. Lu, Q, Wei D, Zhou J, Xu J, Cheng J, et al. (2013) Preparation of PolymerFunctionalized Iron Oxide Nanoparticles and Their Biomedical Properties. Chin. J Chem 3: 40-406.

8. Yang J, Lee CH, Ko HJ, Suh JS, Yoon HG, et al. (2007) Multifunctional MagnetoPolymeric Nanohybrids for Targeted Detection and Synergistic Therapeutic Effects on Breast Cancer. Angew Chem Int 46: 8836-8839.

9. Steitz B, Hofmann H, Kamau SW, Hassa PO, Hottiger MO, et al. (2007) Characterization of $\mathrm{PEl}$-coated superparamagnetic iron oxide nanoparticles for transfection: Size distribution, colloidal properties and DNA interaction. J Magn Mater 3: 300-305.

10. Petri-Fink A, Hofmann $H$ (2007) Superparamagnetic iron oxide nanoparticles (SPIONs): from synthesis to in vivo studies-a summary of the synthesis, characterization, in vitro, and in vivo investigations of SPIONs with particular focus on surface and colloidal properties. NanoBioscience, IEEE Transactions on 6: 289-297.

11. Israel LL, Lellouche E, Kenett R, Green O, Michaeli S, et al. (2014) Ce3/4+ Cation-Functionalized Maghemite Nanoparticles Towards siRNA-Mediated Gene Silencing. Journal of Materials Chemistry B 2: 625-6225.

12. Abid AD, Anderson DS, Das Gk, Winkle VLS, Kennedy IM (2013) Novel lanthanide-labeled metal oxide nanoparticles improve the measurement of in vivo clearance and translocation. Particle and fibre toxicology 203 10: 1.

13. Dutta P, Manivannan A, Seehra MS, Shah N, Huffman GP (2004) Magnetic properties of nearly defect-free maghemite nanocrystals. Physical Review B 70: 74428.

14. Haviv AH, Grenèche JM, Lellouche JP (2010) Aggregation control of hydrophilic maghemite (gamma-Fe2O3) nanoparticles by surface doping using cerium atoms. J Am Chem Soc 32: 259-252.

15. Gossuin Y, Gillis P, Hocq A, Vuong QL, Roch A (2009) Magnetic resonance relaxation properties of superparamagnetic particles. Wiley Interdisciplinary Reviews Nanomedicine and Nanobiotechnology 299-30.

16. Kluchova K, Zboril R, Tucek J, Pecova M, Zajoncova L, et al. (2009) Superparamagnetic maghemite nanoparticles from solid-state synthesis-Their functionalization towards peroral MRI contrast agent and magnetic carrier for trypsin immobilization. Biomaterials 30: 2855-2863.

17. Israel LL, Kovalenko EI, Boyko AA, Sapozhnikov AM, Rosenberger I (2015) Towards hybrid biocompatible magnetic rHuman serum albumin-based nanoparticles: use of ultra-small (CeL n ) 3/4+ cation-doped maghemite nanoparticles as functional shell. Nanotechnology 26: 04560.

18. Peppas BL, Blanchette JO (2014) Nanoparticle and targeted systems for cancer therapy. Advanced drug delivery 206-22.

19. Kanasty R, Dorkin JR, Vegas A, Anderson D (2013) Delivery materials for siRNA therapeutics. Nat Mater 2: 967-977.

20. Davis ME (2009) The first targeted delivery of siRNA in humans via a selfassembling, cyclodextrin polymer-based nanoparticle: from concept to clinic. Mol Pharm 659-68.

21. Bartlett DW, Davis ME (2007) Physicochemical and biological characterization of targeted, nucleic acid-containing nanoparticles. Bioconjug Chem 8: 456-468.

22. Lieskovan HS, Heidel JD, Bartlett DW, Davis ME, Triche TJ (2005) Sequencespecific knockdown of EWS-FLI by targeted, nonviral delivery of small interfering RNA inhibits tumor growth in a murine model of metastatic Ewing's sarcoma. Cancer Res 8984-92.
23. Bao Y, Jin Y, Chivukula P, Zhang J, Liu Y, et al. (2013) Effect of PEGylation on biodistribution and gene silencing of siRNA/lipid nanoparticle complexes. Pharm Res 30: 342-35.

24. Belliveau NM, Huft J, Lin PJ, Chen S, Leung AK, et al. (2015) Microfluidic Synthesis of Highly Potent Limit-size Lipid Nanoparticles for In Vivo Delivery of siRNA. Mol Ther Nucleic Acids e37.

25. Biswas S, Deshpande PP, Navarro G, Dodwadkar NS, Torchilin VP (2013) Lipid modified triblock PAMAM-based nanocarriers for siRNA drug co-delivery. Biomaterials 34: 289-30.

26. Liu J, Gu C, Cabigas EB, Pendergrass KD, Brown ME, et al. (2013) Functionalized dendrimer-based delivery of angiotensin type receptor siRNA for preserving cardiac function following infarction. Biomaterials 34: 3729-36.

27. Boyer C, Teo J, Phillips P, Erlich RB, Sagnella S, et al. (2013) Effective delivery of siRNA into cancer cells and tumors using well-defined biodegradable cationic star polymers. Mol Pharm 2435-44.

28. Cho HY, Averick SE, Paredes E, Wegner K, Averick A, et al. (2013) Star polymers with a cationic core prepared by ATRP for cellular nucleic acids delivery. Biomacromolecules 4: 262-267.

29. Soutschek J, Akinc A, Bramlage B, Charisse K, Constien R, et al. (2004) Therapeutic silencing of an endogenous gene by systemic administration of modified siRNAs. Nature 73-8.

30. Jeong JH, Mok H, Oh YK, Park TG (2009) siRNA conjugate delivery systems. Bioconjug Chem 20: 5-4

31. Heinemann D, Schomaker M, Kalies S, Schieck M, Carlson R, et al. (2013) Gold nanoparticle mediated laser transfection for efficient siRNA mediated gene knock down. PLoS One e58604.

32. Buchman YK, Lellouche E, Zigdon S, Bechor M, Michaeli S, et al. (2013) Silica nanoparticles and polyethyleneimine (PEI)-mediated functionalization: a new method of PEI covalent attachment for siRNA delivery applications. Bioconjug Chem 24: 2076-87

33. Siu KS, Chen D, Zheng X, Zhang X, Johnston N, et al. (2014) Non-covalently functionalized single-walled carbon nanotube for topical siRNA delivery into melanoma. Biomaterials 35: 3435-42.

34. Israel LL, Lellouche E, Ostrovsky S, Yarmiayev V, Bechor M, et al. (2015) Acute in vivo Toxicity Mitigation of PEl-Coated Maghemite Nanoparticles using Controlled Oxidation and Surface Modifications towards siRNA Delivery. ACS applied materials \& interfaces 15240-15255.

35. Lellouche JP, Michaeli, Israel LL, Lellouche E, Buchman K (2004) Magnetic inorganic iron-based nanoparticles - generalities and use in drug delivery. WO 20447608 A2040925, January 9th, 204.

36. Khodadust R, Unsoy G, Yalcin S, Gunduz G, Gunduz U (2013) PAMAM dendrimer-coated iron oxide nanoparticles: synthesis and characterization of different generations. J Nanopart Res 15: 1-13.

37. Baker A, Saltik M, Lehrmann H, Killisch I, Mautner V, et al. (1997) Polyethylenimine (PEI) is a simple, inexpensive and effective reagent for condensing and linking plasmid DNA to adenovirus for gene delivery. Gene Ther 4: 773-782.

38. Massart R, Dubois E, Cabuil V, Hasmonay E (1995) Preparation and properties of monodisperse magnetic fluids. J Magn Mater 1-5.

39. Krepelová A, Newberg J, Huthwelker T, Bluhm H, Ammann M (2010) The nature of nitrate at the ice surface studied by XPS and NEXAFS. Phys Chem Chem Phys 2: 8870-8880.

40. Ma L, Yang X, Gao L, Lu M, Guo C (2013) Synthesis and characterization of polymer grafted graphene oxide sheets using a $\mathrm{Ce}(\mathrm{IV}) / \mathrm{HNO} 3$ redox system in an aqueous solution. Carbon 53: 269-276

41. Makino K, Mossoba MM, Riesz P (1983) Chemical effects of ultrasound on aqueous solutions. Formation of hydroxyl radicals and hydrogen atoms. The journal of physical chemistry 369-377

42. Kenett RSZ, Amberti SD (2016) Modern Industrial Statistics: with applications in R, MINITAB and JMP. (2ndedn) John Wiley and Sons, Chichester 377-379.

43. Kaiser E, Colescott RL, Bossinger CD, Cook PI (1970) Color test for detection of free terminal amino groups in the solid-phase synthesis of peptides. Anal Biochem 34: 595-598.

44. Sarin VK, Kent SB, Tam JP, Merrifield RB (1981) Quantitative monitoring of solid-phase peptide synthesis by the ninhydrin reaction. Anal Biochem 7: 47-57. 